Portland State University

PDXScholar

Summer 8-27-2014

\title{
The Responsibility to Protect and International Law: Moral, Legal and Practical Perspectives on Kosovo, Libya, and Syria
}

William R. Blackford

Portland State University

Follow this and additional works at: https://pdxscholar.library.pdx.edu/open_access_etds

Part of the Comparative Politics Commons

Let us know how access to this document benefits you.

Recommended Citation

Blackford, William R., "The Responsibility to Protect and International Law: Moral, Legal and Practical Perspectives on Kosovo, Libya, and Syria" (2014). Dissertations and Theses. Paper 2532.

https://doi.org/10.15760/etd.2529

This Thesis is brought to you for free and open access. It has been accepted for inclusion in Dissertations and Theses by an authorized administrator of PDXScholar. Please contact us if we can make this document more accessible: pdxscholar@pdx.edu. 
The Responsibility to Protect and International Law: Moral, Legal and Practical Perspectives on Kosovo, Libya, and Syria

$$
\text { by }
$$

William R. Blackford

A thesis submitted in partial fulfillment of the requirements for the degree of

\author{
Master of Arts \\ in \\ Political Science
}

Thesis Committee:

David Kinsella, Chair

Bruce Gilley

Lindsay Benstead

Portland State University

2014 


\begin{abstract}
Humanitarian intervention has long been a secondary or tertiary concern in a security driven international system. Since NATO's intervention during the Kosovo crisis in 1999 there have been significant developments in both the language and form of humanitarian intervention as a matter of international law. The events in Kosovo sparked debate about how to handle humanitarian crisis in the future and thus humanitarian intervention evolved into a redefinition of sovereignty as responsibility and the Responsibility to Protect. The Responsibility to Protect has had a number of opportunities to continue to evolve and assert itself in an international legal context throughout the ensuing years since the Kosovo intervention.

The purpose of this research is to explore the moral, legal and practical implications of the Responsibility to Protect doctrine. Classical and contemporary theories of international relations and moral philosophy are applied in the context of the Responsibility to Protect and its effect upon the international system and specific states to cultivate a sense of the development of the norm and different actors' attitudes towards it. A literature review is conducted to show the practical and conceptual issues inherent in the framework of the Responsibility to Protect. The norm is then applied to the cases of Kosovo, Libya, and Syria to assess its effect in practice and determine its origins. The analysis of these case studies leads to a number of conclusions regarding its effectiveness and future application.
\end{abstract}


The case studies chosen for this research are Kosovo, Libya, and Syria. The case of Kosovo helps to establish a humanitarian intervention framework, the need for redefinition, and the beginning of the Responsibility to Protect. Libya shows the first strong case for the positive application of the Responsibility to Protect in a practical sense. The non-intervention in Syria shows the difficult political issues involved in intervention and presents uncertainty as to the positive development of the norm. These cases clearly show the myriad of practical challenges to RtoP that are borne out the theoretical, moral issues embedded in its philosophy.

The conclusion drawn from the literature review and subsequent case studies is that the current efforts to assert the Responsibility to Protect are aimed at the wrong areas of international law and states, and that the norm is not developing positively in a linear pattern. To successfully promote its acceptance the Responsibility to Protect must build institutional linkages to make intervention more cost effective, exercise the regional options available to promote and ensure the legitimacy of intervention, and assure the acceptance of RtoP by the major powers in the Security Council. 


\section{Table of Contents}

List of Tables.

History of Humanitarian Intervention and RtoP................................................... 6

Defining the Responsibility to Protect .................................................................. 13

Theoretical Perspectives .......................................................................................... 19

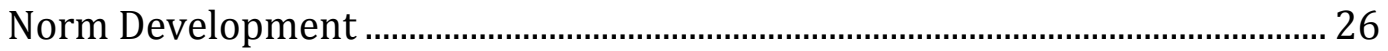

Chapter 2: Central Issues Explored ......................................................................................... 34

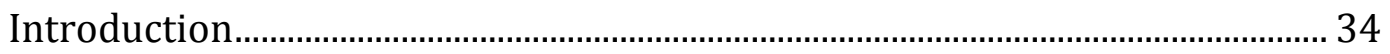

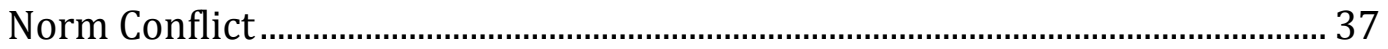

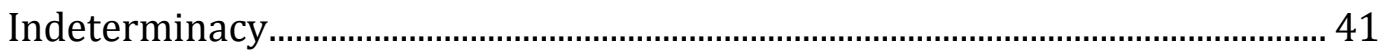

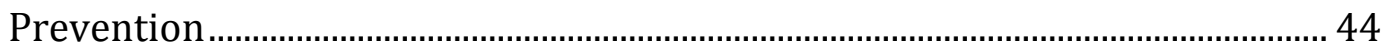

The Redefinition of Sovereignty ………............................................................... 50

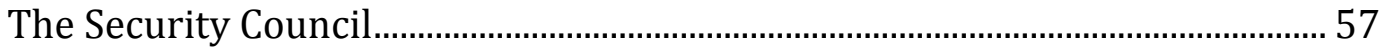

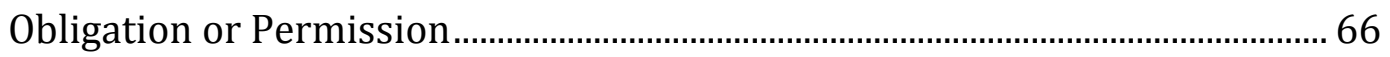

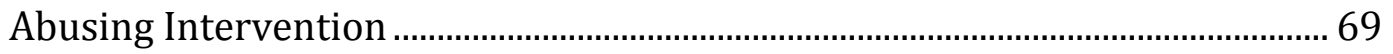

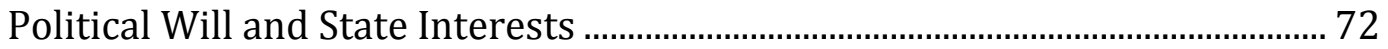

Chapter 3: Case Studies - Kosovo, Libya, Syria ……........................................................................ 


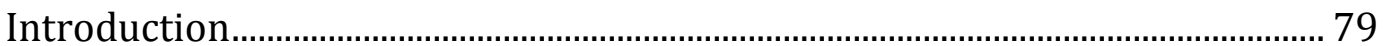

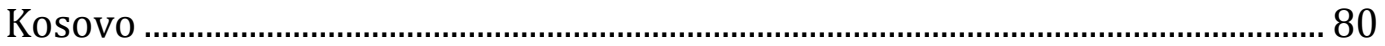

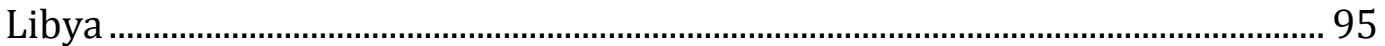

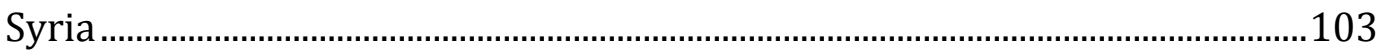

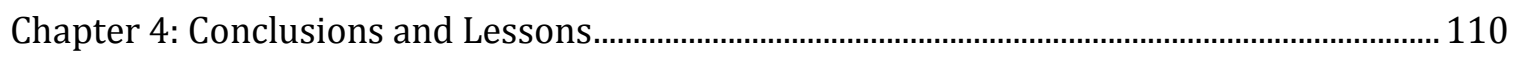

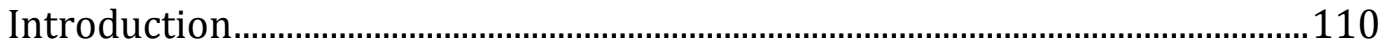

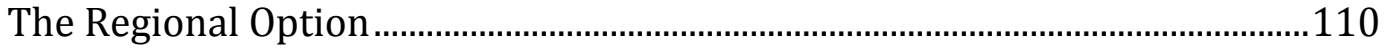

The Institutional Approach.................................................................................. 114

Peacebuilding Commission ..................................................................................116

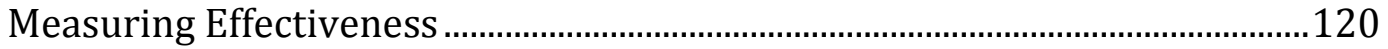

United States Position and Policy ........................................................................122

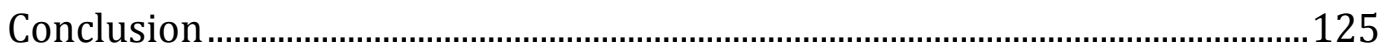

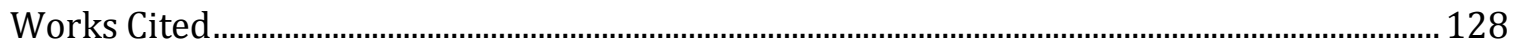


List of Tables

TABLE 1: Security Council Resolutions by Country 


\section{Chapter 1: Overview}

\section{Introduction}

The Responsibility to Protect (RtoP) is a conceptual and practical tool developed by states, international organizations such as the United Nations, and international law scholars for the purpose of attempting to standardize and clearly form a comprehensive approach to military and non-military intervention and engagement with nation-states committing or in danger of committing human rights abuses at a determined level of severity. In essence, RtoP relies on a redefinition of sovereignty that differs from the traditional Westphalian concept of sovereignty and relies on three pillars in order to justify humanitarian intervention from a moral and legal standpoint. Sovereignty as responsibility attempts to redirect the focus of sovereignty from classical definitions regarding nonintervention to the responsibility that rulers or those in power have to protect the lives of their citizens, and thereby the responsibility that the international community has to protect those same citizens in lieu of domestic leadership. Central also to this redefinition is the proposed action plan, which involves prevention, reaction, and rebuilding to enforce RtoP.

The task that the International Commission on Intervention and State Sovereignty (ICISS) and the United Nations General Assembly with the support of the Secretary General have undertaken is a challenging one. Any alteration or 
evolution of established international norms is often contentious and conceptually problematic. The interested parties have made some interesting progress and uncovered a number of conceptual, legal, and moral issues with the basic logic of RtoP and humanitarian intervention. In order to understand these challenges, this work explores the traditional concepts of sovereignty and places them in juxtaposition to the attempt at redefinition.

This work outlines these issues and concepts in a logical and intuitive way in order to foster a deeper understanding of the logic of humanitarian intervention from an international legal perspective. The first chapter develops an understanding of the Responsibility to Protect itself as a concept, including a precise definition of RtoP, discussion of the background of RtoP, the development of humanitarian intervention, further development of the definitions and concepts important to RtoP, and brief overview of the main issues and controversies. This initial chapter is meant to provide a foundation within the realm of international relations upon which to build the deeper understanding of the issues inherent in the adoption of RtoP. The second chapter of the study delves into a deeper understanding of RtoP with particular reference to the conceptual, practical, and theoretical issues laid out in the first chapter. The second section is concerned largely with the moral and legal issues and concepts inherent in RtoP and its development as a potential norm in international law. The chapter explores the challenges presented by RtoP, why they exist, and how they may be overcome in some cases. Chapter three of the study examines the current status of RtoP as an international legal concept by looking at 
case studies of some of its most recent applications or evocations in Libya and Syria preceded by an examination of humanitarian intervention in Kosovo in 1999. The fourth and final chapter draws some conclusions from the preceding analysis and suggests some important areas of focus for the development of RtoP. This includes some feasible approaches and factors to be considered.

The proceeding examination of the Responsibility to Protect is conducted largely as a literature review with a brief case study to explore practical applications of the literature. The opinions of the prevailing international legal scholars, international organizations, and heads of state are essential in providing an understanding of an international legal norm as complex and contested as the Responsibility to Protect. The status and development of the norm is reflected through the bodies of work published by those influential in the field, i.e. those who are capable of shaping normative developments in international law. The case study conducted between the Kosovar, Libyan, and Syrian conflicts serves to highlight the difficulties inherent in applying a concept as nebulous as RtoP and provide further context for the literature review.

The analysis concludes that there are many operational and moral problems inherent in the RtoP concept and its application, or lack thereof, to real world events. The Responsibility to Protect as it currently stands is indeterminate, ethnocentric, and paternalistic. The means by which the ICISS and some members of the United Nations are attempting to achieve their goals are ill-formed and based on a particular worldview applied universally through an organization, the United 
Nations, that is not entirely based upon the equality of its members in practice. Whether or not this means that the entire Responsibility to Protect doctrine should be abandoned is a question with a less definite answer. The conclusion in Chapter 4 attempts to address these problems and come up with potential solutions, however it may come to pass that these issues cannot be resolved to the satisfaction of all United Nations members states.

\section{Goals}

Before beginning any in-depth discussion about the Responsibility to Protect it is necessary to clarify a number of things with respect to the goals of this study in order to avoid potential misunderstandings. The purpose of this exploration of the Responsibility to Protect is not to claim or prove that the inherent goal of RtoP is morally wrong or misguided - that goal being the prevention of mass murder, genocide, ethnic cleansing, etc. In fact, as the history shows, those portions of RtoP are already enshrined in international treaties and conventions (The Geneva Conventions, and The Convention on the Prevention and Punishment of the Crime of Genocide, e.g.) and thereby generally accepted as legitimate international law by and large. I do not wish to question the moral legitimacy of preventing genocide and crimes and against humanity, merely the mechanisms by which this end is achieved.

The goal of this study, therefore, is to engender a deeper understanding of the function and logic of applying a decidedly Universalist norm like RtoP and the issues created thereby in order to assess its affect upon the behavior of nationstates (referred to elsewhere as "compliance-pull"). The potential issues related to 
RtoP are that it brings with it a number of assumptions and inferences about global society and Western civilization in general that can be problematic for certain perspectives - these inferences may reflect the privileged position of the powerful, Western societies that have the most sway within international decision making bodies like the United Nations. This study shows that many of the values and theoretical foundations of RtoP are distinctly ethnocentric, as are some of the mechanisms for enforcing it. It is also the attempt to redefine the age-old principle of sovereignty that is problematic - the Commission asserts their redefinition as though it is fact, without much discussion to support it. These issues may negatively affect the adoption of RtoP norms and thereby hinder the underlying goal. It is my hope that exposure of these issues to critical analysis will reveal other paths.

Furthermore, a fair amount of the controversy surrounding RtoP is the tension between the sometimes ideologically opposed and geographically split Permanent Five (P5) members of the Security Council - namely, Russia and China as one bloc and the United States, France, and the United Kingdom as another. There is no dearth of academic literature and analysis that shows the potentially problematic divide between members of the P5 and the possibility of a veto effectively blocking UN Security Council action in a case that may call for the RtoP framework to be asserted and an intervention carried out. Although there are almost certainly vital state interests besides RtoP at stake in these situations (the case of Syria, for example, will be examined later), the lack of application of the RtoP principle in certain cases serves to highlight this ideological divide between great powers and 
members of the P5 regarding the normative conflict between sovereignty, nonintervention, and human security.

It is the ideological content of RtoP that this study addresses, i.e. the mechanisms by which a universal morality is asserted by a certain grouping of state and non-state actors and what those mechanisms reflect not only about the morality itself but those who assert it so vigorously. The fact that this ideological split, shown both in the Security Council and generally abroad, can be demonstrated through the literature on RtoP serves to highlight the goals of this study, which is merely to question the normative status of concepts that are generally considered to be "good," like humanitarian intervention. Keeping these goals in mind, this study proceeds with an examination of the history of humanitarian intervention.

\section{History of Humanitarian Intervention and RtoP}

It goes without saying that the evolution of human protection and intervention has a long history that reaches back through centuries of human development ${ }^{1}$. However, for the purposes of this study of the responsibility to protect, we begin our analysis of human protection and humanitarian intervention with the Geneva Conventions in 1949. As Elizabeth Ferris writes, "After World War II, international human rights law developed as a cornerstone of the new international order" (2011, 6). So although the concept of human rights and human protection certainly existed

${ }^{1}$ Elizabeth Ferris claims, "Modern humanitarianism is generally dated to the midnineteenth century, when a remarkable reform movement grew up in Europe and North America" $(2011,8)$. She also writes at length about the humanitarian principles inherent in Islam. She places the start of international humanitarian law at the 1864 Geneva Convention. 
before 1949, the humanitarian developments that came out of World War II are most instructive for our purposes here. Most succinctly, humanitarian intervention is defined as, "the threat or use of force across state borders by a state (or group of states) aimed at preventing or ending widespread and grave violations of fundamental human rights of persons other than the nationals of the intervening state and without the permission of the state within which force is applied" (Farer, Archibugi, Brown, Crawford, Weiss and Wheeler. 2005, 212). Some examples of humanitarian interventions between 1949 and the early 1990's are India in East Pakistan in 1971, Vietnam in Cambodia in 1978, Tanzania in Uganda in 1979. According to Thakur (2009) these Cold War era interventions were rife with humanitarian rhetoric and "pseudo interventions." In other words, many of these interventions were politically dubious and carried out in an ad hoc manner. The Post-War period was one in which the primary international body for making determinations leading to humanitarian interventions, the United Nations Security Council, was effectively frozen by ideological differences.

The Responsibility to Protect began in the 1990's with a surge in the frequency of international humanitarian interventions after the end of the Cold War tensions that largely froze multilateral action in the United Nations Security Council due to indulgent use of the veto and other ideological issues (Nahory 2004). Examples of the most prominent 1990's interventions are those that occurred in Somalia, Kosovo, and Rwanda, many of which are widely considered to be failures. However, it was the relative failure of these operations to halt or prevent abuses 
effectively that led to the formulation of RtoP. As Ekkehard Strauss notes, "the responsibility to protect was developed as a response to the lack of Security Council action regarding the situation in Kosovo that generated more general debate about the gap between legality and legitimacy" $(2010,46)$. It was in the wake of Security Council immobilization due to ideology and failed attempts to conduct humanitarian intervention operations that a need for something new surfaced.

In The Oxford Handbook on the United Nations Ramesh Thakur (2009) highlights one of the fundamental differences between humanitarian intervention and the Responsibility to Protect. This difference is shown most clearly in how the debate over each concept is carried out. Thakur writes in "Humanitarian Intervention," "The first debate, by pointing to possible justification for intervention outside the UN framework, concentrated on developing and amplifying the exception to the rule. The second seeks to elaborate a new rule that itself justifies and may require international intervention" $(2009,2)$. This distinction is paramount to the discussion - with this refocusing of the debate the question now centers on how, why, and when we may use the UN to carry out humanitarian intervention legally and effectively, whereas previously the question was how to carry out humanitarian intervention outside the UN framework because the intervention violated a well-established United Nations principle - sovereignty. Humanitarian intervention outside of the UN is shown in the case study on Kosovo in Chapter 3. Since then humanitarian intervention has attempted to move from an exception to the rule to the formation of a rule in and of itself. Reframing the argument in favor of 
a responsibility to protect as opposed to humanitarian intervention also allows proponents to focus on aspects other than the intervention piece which is explicitly implied as the end-goal, these other aspects being the prevention and rebuilding pieces of RtoP. In contrast to humanitarian intervention, R2P "provides conceptual, normative and operational linkages between assistance, intervention and reconstruction" (Thakur 2009, 13). The language of RtoP is meant to shift focus directly towards the populations in need of assistance and develop effective routes for providing that assistance.

In 1999, then Secretary General of the United Nations Kofi Annan expressed his thoughts on the current state of humanitarian intervention and the responsibility to protect. Kofi Annan's goal was to attempt to reach some kind of consensus on the ill-defined concept of humanitarian intervention in order to more effectively prevent atrocities like the Rwandan Genocide (Badescu and Bergholm 2009). Subsequently the International Commission on Intervention and State Sovereignty was established and their report published in 2001 was titled The Responsibility to Protect. This became the premier referential document for the Responsibility to Protect concept. The report addresses the normative conflicts presented by humanitarian intervention and state sovereignty. As legal precedent to the Responsibility to Protect the ICISS Document cites the Universal Declaration of Human Rights; the four Geneva Conventions and the two Additional Protocols on international humanitarian law in armed conflict; the 1948 Convention on the Prevention and Punishment of the Crime of Genocide; the two 1966 Covenants 
relating to civil, political, social, economic and cultural rights; and the adoption in 1998 of the statute for the establishment of an International Criminal Court. Some tenets of the 2001 ICISS Report was officially endorsed by the United Nations General Assembly in what is generally referred to as the 2005 Outcome Document. In paragraphs 138 and 139 the General Assembly affirms the ICISS's assertion that individual states are responsible for protecting their populations from genocide, war crimes, ethnic cleansing, and crimes against humanity and that the international community, through the United Nations, also has a responsibility to protect populations from the same crimes (U. N. General Assembly 2005). This second responsibility is the central tenet of RtoP. In 2006 the Security Council reaffirmed the conclusions reached by the General Assembly in paragraphs 138 and 139 of the Outcome Document by passing Resolution 1674 (U. N. Security Council 2006).

It was at this time that the concept or RtoP began to separate itself conceptually from the concept of humanitarian intervention. Kofi Annan, the former Secretary General of the United Nations, began to push for a different agenda; "Under the impact of the two contrasting experiences of Rwanda and Kosovo, Annan urged member states to come up with a new consensus on the competing visions of national and popular sovereignty and the resulting 'challenge of humanitarian intervention'” (Thakur 2009, 12). There was a realization by Annan and other members of the international community that humanitarian intervention could work in theory, and that the international community required some kind of framework for it to work effectively - this became the Secretary General's goal. 
In 2004 before the outright acceptance of RtoP principles in the Outcome Document, in A More Secure World, the General Assembly affirms, "There is a growing recognition that the issue is not the 'right to intervene' of any State, but the 'responsibility to protect' of every State when it comes to people suffering from avoidable catastrophe" (U. N. General Assembly 2004, 56). The General Assembly also endorses a "collective international responsibility to protect" as an "emerging norm," and references the Security Council as the legitimate body through which to act in reference to RtoP. This endorsement and recognition of an emerging norm eventually led to the resolution that was the 2005 Outcome Document. There were some roadblocks on the way to RtoP's iteration in the 2005 Outcome Document. As one might expect, the document itself went through a number of revisions. On August 5 UNGA President Jean Ping presented a revised draft, wherein the document "limited the scope" of RtoP with respect to the triggering mechanisms for its enforcement (genocide, war crimes, ethnic cleansing and crimes against humanity) and "They acknowledged that the international community, through the United Nations, also had the 'obligation' - changed from 'responsibility' - to use [...] peaceful means" in cases where RtoP enforcement may apply (Strauss 2010, 30). Here the second pillar of RtoP is referred to as an obligation of states to act as opposed to merely a responsibility or permissive norm that allows them to act if they wish.

The United States had some key reservations to the resolution. As Strauss writes, "The United States requested, inter alia, to drop the reference to incitement 
and change the wording back to 'responsibility' when describing the role of the international community" $(2010,30)$. Although incitement ${ }^{2}$ made it into the final document, any mention of obligation to the international community is omitted. The language of the final document also changes the "unwilling and unable" to protect their populations in triggering the third pillar of RtoP to "manifestly fails," which is arguably less subjective than the former and sets the bar for intervention a bit higher. Strauss notes that countries "questioned who could determine legally that a member state was 'unwilling and unable' to protect their populations" (Strauss 2010, 32). Manifest failure, however, may be easier to determine. The proceeding examination shows that the hesitance to use strong language in reference to humanitarian intervention triggers, especially by the U.S. and other great powers, continues to be a problem as the norm evolves.

The Responsibility to Protect is now considered part of the lexicon of international relations and has effectively replaced humanitarian intervention, though the latter is still sometimes referred to with negative connotations. The evolution from humanitarian intervention to a responsibility to protect shifts the focus of the debate and attempts to redefine a concept central to international relations. One of the most important aspects of the redefinition is the focus on the recipients of aid and their protection as opposed to potential violations of

2 Wording from the Outcome Document: "This responsibility entails the prevention of such crimes, including their incitement, through appropriate and necessary means [emphasis mine]" (U. N. General Assembly 2005, 31). 
sovereignty. The more recent history of RtoP and its applications is addressed more in depth in the third chapter on the Libyan and Syrian civil wars.

\section{Defining the Responsibility to Protect}

It is important here to attempt a definition of exactly what it is the Responsibility to Protect is attempting to do or accomplish. This is done by exploring the main tenets of RtoP as they are presented in the ICISS report and other official documentation from the United Nations as well as analysis of those works from international legal scholars. In defining the Responsibility to Protect as accurately as possible we may then explore the central issues presented by its implementation with a fuller understanding of their impact. As addressed later in the work, some of the concepts contained within RtoP are difficult to define or determine. As a result, this section on defining RtoP refers mainly to the core texts that introduce and affirm it, i.e. the 2001 ICISS Report and subsequent United Nations resolutions. This is done in an attempt to present RtoP as what international organizations are trying to accomplish, not exactly what is being done.

The Basic Principles of the Responsibility to Protect are outlined by the International Commission on Intervention and State Sovereignty in the 2001 document The Responsibility to Protect. Summarized, the basic principle of RtoP is, "Where a population is suffering serious harm, as a result of internal war, insurgency, repression or state failure, and the state in question is unwilling or unable to halt or avert it, the principle of non-intervention yields to the international responsibility to protect" (ICISS 2001, XI). What the ICISS is essentially 
saying here is that states are responsible as sovereigns for the protection of their citizens (indeed, this responsibility is a prerequisite for sovereignty) and that any failure of this responsibility allows the international community to intervene in order to facilitate said protection, even against the wishes of the sovereign who has allegedly failed said responsibility. As succinctly stated by Badescu and Bergholm,

The central normative tenet of R2P is that state sovereignty entails responsibility and, therefore, each state has a responsibility to protect its citizens from mass killings and other gross violations of their rights. However, if a state is unable or unwilling to carry out that function, the state abrogates its sovereignty, and the responsibility to protect devolves onto international actors. $(2009,288)$

These concepts are also known as the Three Pillars of the Responsibility to Protect. The first pillar is the responsibility of the sovereign powers to their own populations, the second is the responsibility to the international community to enforce or support the fulfillment of this responsibility if need be, and the third is potentially the permission to employ coercive measures up to and including military intervention in order to assure that these responsibilities are being met.

The 2005 Outcome document penned by the United Nations General Assembly reaffirms the ICISS concepts;

Each individual State has the responsibility to protect its populations from genocide, war crimes, ethnic cleansing and crimes against humanity. This responsibility entails the prevention of such crimes, including their incitement, through appropriate and necessary means. We accept that responsibility and will act in accordance with it. (United Nations 2005)

The document goes on to state that Chapter VII enforcement by the Security Council is a viable option in these circumstances. The first pillar is the acknowledgement of the responsibility of sovereigns to protect their own populations, the second is a 
statement that the international community may help nations to fulfill said responsibility, and the third pillar states generally that if a state manifestly fails in its responsibilities to protect, the international community has the responsibility to use coercive measures such as sanctions and military intervention. Simply stated, the principle characteristics of RtoP are that 1) civilian protection is an international concern, 2) military force is a viable option for policing this concern, 3) regional arrangements may be effective in this enforcement and 4) The United Nations Security Council is the most legitimate body through which to achieve this military civilian protection (Bellamy 2011).

The ICISS is attempting to redefine sovereignty; therefore it is prudent here to examine what it is that they are changing it to as part of our definition. The concept of sovereignty as a legal principle in international law extends back to the 1648 Peace of Westphalia. The peace established for the first time external political boundaries and established the concept of a sovereign's internal jurisdiction over their population. The concept of sovereignty is generally considered to be enshrined in Article 2 (7) of the United Nations Charter, which states, "Nothing contained in the present Charter shall authorize the United Nations to intervene in matters which are essentially within the domestic jurisdiction of any state" (United Nations 1945), but provides exceptions under Chapter VII of the Charter which concerns sanctions and military actions. What is "essentially" within in the domestic jurisdiction of a state has never been precisely defined, however Article 2 provides a guide post for 
navigating through the difficult business of ensuring international peace and security.

Westphalian sovereignty is not the only kind of sovereignty, however. Stephen Krasner's Sovereignty: Organized Hypocrisy (1999) outlines four different types of interrelated sovereignty; international legal, interdependence, domestic, and Westphalian. International legal sovereignty is established by mutual recognition of statehood between states and their capacity to act as states. Interdependence sovereignty refers to the ability of states to regulate cross border trade and globalization. Domestic sovereignty is perhaps the most widely-known concept, and refers to internal political authority structures and how those authorities exercise effective control within their own border. Finally, Westphalian sovereignty is based on two principles; "territoriality and the exclusion of external actors from domestic authority structures" (Krasner 1999, 4-20). Domestic and Westphalian sovereignty are the concepts most relevant to our discussion of sovereignty here. The Commission and the Responsibility to Protect are attempting to redefine the concept of sovereignty in a way that diminishes the effect or absoluteness of domestic and Westphalian sovereignty.

With respect to the Responsibility to Protect's definition of sovereignty, the Commission states, "There is no transfer or dilution of state sovereignty. But there is a necessary re-characterization involved: from sovereignty as control to sovereignty as responsibility in both internal functions and external duties" (ICISS 2001,12). This is perhaps the most precise description of what RtoP is attempting to 
accomplish vis-à-vis sovereignty. According to the ICISS definition a prerequisite of sovereign authority is the ability, actual or potential, of that sovereign to protect their populations from atrocities such a war crimes, ethnic cleansing, and genocide. This protection entails not only shielding one's population from outside forces that my commit these crimes, but also internal forces, whether those be in the government itself or some kind of paramilitary organization within the country's borders.

With respect to the severity or triggers for RtoP the ICISS Document provides, "large scale loss of life" or "ethnic cleansing," that is "occurring or imminent." As a more general description they provide cases of "conscienceshocking situations crying out for action" (ICISS 2001, XIII). These situations generally cover the conventions and protocols against genocide, ethnic cleansing, crimes against humanity, and war crimes. More in-depth discussion of these terms and situations is not provided within the document except for further references to well-established international norms against genocide and ethnic cleansing. In this sense RtoP provides an impetus for action only in "obvious" cases of abuse such as is already covered by the existing treaties and conventions against genocide, etc. Furthermore, there is no in-depth discussion of what qualifies as "imminent," though subsequent scholarly analysis of the issue has attempted to clarify this as is explored subsequently in this study. Ideally, continued application of the norm will help to clarify these concepts. 
On the subject of a legal threshold for determining legitimate intervention the Commission adheres largely to Just War theory principles - "in the Commission's judgement all the relevant decision making criteria can be succinctly summarized under the following six headings: right authority, just cause, right intention, last resort, proportional means and reasonable prospects" (ICISS 2001, 32). These headings are all part of the jus ad bellum tradition of Just War theory, i.e. the internationally accepted guidelines by which nations justify the resort to armed conflict. To expand briefly, right authority requires that the declaration of war, as it were, comes from a legitimate source, in this case the United Nations Security Council. Just cause and right intention require that the purpose of the military action be very narrowly and specifically defined, in this case with the goal of ending or preventing atrocities and supporting the responsibility to protect of the sovereign state as opposed to securing power in the region or bringing about a change in leadership. The last resort principle requires that all other avenues have been explored and attempted, i.e. Chapter VI Security Council mechanisms on the pacific settlements of disputes. Proportional means requires that the response be just severe enough to halt the atrocities, and should not cause undue stress or long-term injury. Reasonable prospects simply means that the intervening force must have a reasonable chance of succeeding at their objective. In addition to these principles, Brunstetter and Braun suggest that we also consider the probability of escalation as a valid Just War principle in their work on applications of small-scale force (2013, 98) such as we might see in RtoP operations. This essentially means that we must 
consider what affect the intervention will have upon the level of violence being committed. For example, atrocities may ramp up as outside military intervention draws near in a last ditch effort of sorts, as some have argued they did after NATO began their operation in Kosovo.

\section{Theoretical Perspectives}

Before going further into the discussion of the moral issues created by RtoP it is necessary to provide some background context on some of the prevailing theoretical foundations of international relations, philosophy and ethics. This exposition, along with our definition of RtoP, will help ground the proceeding examination of issues in Chapter 2. It would be very possible to pen an entire work on these theories alone (indeed, many have), however that is beyond the scope of this work. This section is meant to provide a brief but as comprehensive as possible overview of the logic central to some international relations theories in order to give context to the RtoP discussion. This work concerns itself mainly with the moral quality of RtoP in this regard and the source of morality from a philosophical perspective. What follows is a review of Chris Brown's International Relations Theory (1992) and some other core texts on the central tenets of cosmopolitan and communitarian theory. Brown's work provides us with a brief overview of the theoretical perspectives that inform our discussion of RtoP and humanitarian intervention in international law.

The central tenets of the cosmopolitan theory of international relations are based largely on the works of Immanuel Kant and his categorical imperative. Kant's 
categorical imperative is a set of guidelines that attempt to explain the way in which universal morality functions. Simply stated, the categorical imperative as laid out in Kant's 1785 work Groundwork of the Metaphysics of Morals relies on three formulations. The first is that one should act only in such a way that they would wish their actions to become a universal law. The second formulation stipulates that human beings are to be treated not as a means to an end but an end in and of themselves. The third formulation simply states, taking into account the first two maxims; every rational being should "Act in accordance with maxims of a universally legislative member for a merely possible realm of ends" (Kant 2002: 37, $46,56)$. In other words, everyone who possesses the ability to reason should always act as a "legislating member" of the possible universal kingdom of ends. This extends to an international legal context in a fairly intuitive way. It ascribes a certain rational mode of behavior to every human being by their very virtue of being human, and that behavior necessarily extends outward to all people everywhere. The cosmopolitan tradition has continued throughout the centuries and finds some of its modern iterations in the works of Charles Beitz (1979), who adapts John Rawls' (1971) concept of justice and fairness, and Daniel Archibugi and David Held (1995). All of these philosophical works are built upon the premise that morality is universal in nature as opposed to relative.

The communitarian theories of international relations differ in a number of fundamental ways. According to Brown, the communitarian perspective differs from cosmopolitanism in that it attempts "to deepen an understanding of communal and 
social solidarity rather than theorise the relationship between the individual and humankind," and furthermore, "The root notion of communitarian thought is that value stems from the community, the individual finds meaning in life by virtue of his or her membership in a political community" $(1992,55)$. In the context of this construction the individual's relationship to humanity as a whole, and thereby universal norms or concepts regarding the human security or freedom that Kant has laid out for us, is less important or less figural than the individual's relationship to their community from which they derive their moral and ethical concepts, and thereby their sense of self.

Michael Walzer explains this concept further with respect to the conception of morality in Thick and Thin (1994). Cosmopolitan morality comes from the topdown, i.e. the Kantian ideal of universal application of the kingdom of ends. In this sense morality is understood and shared by all members of the kingdom of ends, i.e. the kingdom of humanity. The communitarian concept of morality is more grounded in contextual factors and believes that morality is established within a community first and then exported, so to speak. Walzer criticizes the universal application of morality and value systems with an illustrative metaphor;

When full-grown democrats imagine that the rules of discursive engagement are the generative rules of morality in all its kinds, they are very much like an oak tree that, endowed with speech and encouraged to speak freely, solemnly declares the acorn to be the seed and source of the entire forest. But this at least suggests a certain generosity. What is perhaps a better analogue would be provided by an oak tree that acknowledged the full range or arboreal difference and then argued for the cutting down of all those trees, now called illegitimate, that did not begin as acorns. $(1994,13)$ 
These maximalists as Walzer refers to them want to say that the end result (in this case the assertion of a universal moral principle like RtoP) was guided from the beginning by a particular set of ideals, whereas Walzer believes history will show that it only developed slowly over time through a confluence of numerous factors and actions, etc. - this is the oak tree metaphor brought to light. Furthermore, Universalist morality, in asserting its place in a hierarchy of morality, is declaring other viewpoints illegitimate and calling for them to be "cut down" because they do not serve the ends of cosmopolitanism.

According to Hegel, the separation of community and the individual is not only conceptually ill-advised, but actually impossible. He writes that it is not possible "to think of individuals [...] in isolation from the community that has shaped them and constituted them as individuals" (Brown 1992,62). In this sense it is only because of our upbringing in a modern, Western society that we have the privilege believe in a universal, cosmopolitan morality possessed by all. Johann Herder, as quoted in Brown, writes, "The individual is not prior to culture - as the Kantian position would seem to assume - but shaped by it" $(1992,59)$. Furthermore, Herder asserts that culture cannot be consciously created, and collective political identities are found in shared common culture, not sovereignty. Brown also notes that Herder was a staunch pluralist who did not believe in the superiority or hierarchy of any given culture. According to Brown, "his argument is that all peoples have something to offer, their own distinctive contribution to the human family" (72). This formulation is very uniquely constituted to stand in 
opposition to the cosmopolitan concepts advanced by Kant and others. In this context any global society that exists is part and parcel formed by the amalgamation of distinct political units and/or communities through their contributions to the "human family." Though there may be something to gain by bestowing democratic ideals upon other nations in order to make them more peaceful in accordance with our Western conceptions of goodness and morality, these concepts stated by Herder through Brown tell us that there is also something to be lost by replacing the ideals and values of other communities with our own because we view them to be more beneficial.

Not only does the theoretical cosmopolitan ethicist not agree with the assertion that community is the source of values and morality, they believe that alienation from the state or community is a precondition for freedom ${ }^{3}(57)$. What this approach assumes, in opposition to communitarian perspectives, is that the concept of "freedom" or "good will" is not derived from the community itself but they are concepts that exist within all human beings by nature of their humanity and reason, ergo it is derived from the top-down as opposed to the bottom-up and it is the separation from their restrictive or biased communities that allows one to fully realize these universal ideals and concepts for themselves. In this context a separation from community is devoid of negative connotations as it theoretically provides the means by which humans may achieve their freedom as autonomous beings and not means to an end.

${ }^{3}$ Freedom being "moral autonomy for Kant, a free run for the 'passions' for Hume" (Brown 1992). 
For Kant, however, it is man's inability to achieve the kingdom of ends in the third formulation the leads to these separate political communities in the first place. Brown writes, "From a Kantian perspective, it is the inability of man to achieve on earth the universal kingdom of ends required by the third formulation of the categorical imperative, an inability stemming from the radical evil in man's nature, that legitimates the existing structure of separate political communities" $(1992,52)$. According to the Kantian conception, we may however be morally justified in ridding the world of despotism in order to allow all citizens their freedom to not be treated as means to an end. However, war is in and of itself a great hindrance to this freedom and should be halted wherever and whenever possible.

The logic of Responsibility to Protect is undoubtedly based on cosmopolitan ideals, as it ascribes certain fundamental human rights to all people everywhere simply because they are a member of humanity. This is reflected clearly in the language and meaning of RtoP. The conceptual roots of RtoP are "cosmopolitan [...] restrained, or shall we say softened, by the traditional liberal focus on individual rights expressed in the categorical imperatives of first-generation human rights documents and their counterparts in the separately evolved humanitarian law of war" (Farer et. al. 2005, 215). RtoP bases its argument on the presumption that all humans everywhere are accorded certain inalienable rights by their very status as human beings, and it is the responsibility to every sovereign state to ensure that these rights are respected. 
The very existence of an international body like the United Nations is also in line with cosmopolitan theory. Brown writes, "a constitution based on the cosmopolitan right in so far as individuals and states, coexisiting in an external relationship of mutual influences, may be regarded as citizens of a universal state of mankind (ius cosmopoliticum)" (1992, 35-6). One could conceive of the United Nations Charter and the various Conventions as an international constitution based on cosmopolitan ideals wherein the states themselves are citizens of this "universal state of mankind." This potentially gives the United Nations the legitimacy and authority to legislate the universal kingdom of ends from a cosmopolitan viewpoint.

The conflict between these two ideals is oftentimes where we find arguments over the Responsibility to Protect. The Kantian ideal of cosmopolitanism and universal morality clashes with the communitarian concept that ideals and morality are derived from communities and therefore valid in their own way within the community. What RtoP does (whether intentionally or not) by using universal morality is to assert the validity or supremacy of one community ideal over another, and asserts that that community is the largest one, i.e. humanity. Many aspects of RtoP require the coercive assertion of universal norms of morality upon discrete political communities across the world. Even though proponents sometimes address these concerns, they do not often lament them. By building their argument for prevention upon the foundation of a universal value system the cosmopolitan RtoP proponents infer the superiority of their value system which then necessarily replaces the value system of the communities upon which they plan to enforce their 
universal morality. In this sense the potential destruction of community values and cultures as a byproduct of atrocity prevention can be seen as a necessary casualty in the battle for the acceptance of the Responsibility to Protect.

\section{Norm Development}

The evaluation of RtoP requires a discussion of how norms develop in international law from a theoretical and practical perspective. Some of most important milestones for analyzing the development of RtoP as a norm are Rwanda as a case study, the African Union Constitutive Act of 2000, NATO in the 1999 Kosovo operation, the ICISS Document, The High Level Panel on Threats and Challenges in 2004 aka A More Secure World, the Summit Outcome Document in 2005, and Security Council Resolution 1674 (2006). What follows is a discussion of what international legal norms are, how they develop, and how the Responsibility to Protect has progressed in this context. From this understanding we may correctly assess and measure how and in what direction RtoP is moving.

The ultimate object of a norm in international law is to regulate state behavior (Vranes 2006). The goal here is to evaluate the extent to which, if at all, RtoP regulates state behavior and in what way. Alex Bellamy defines a norm as "shared expectations of appropriate behavior for actors with a given identity" $(2010,160)$. In the present context the shared expectation is that sovereign states will behave a certain way or within certain limits towards their populations and that if they do not then other actors may step in to fulfill this responsibility. The actors with a given identity are member-states of the United Nations by a narrow 
definition, and all nation-states in the international community of states by a much broader, cosmopolitan definition. Bellamy expands upon this concept further with direct reference to RtoP;

The test of whether pillars two and three are properly called norms is the extent to which there is a shared expectation that 1) governments and international organizations will exercise this responsibility, that 2) they recognize a duty and right to do so, and that 3 ) failure to act will attract criticism from the society of states. $(2010,161)$

The failure to act piece of Bellamy's quote is an interesting one that is difficult to determine. Bellamy goes on to state that the indeterminate nature ${ }^{4}$ of the second and third pillars of RtoP weakens its "compliance-pull," and thereby the shared expectations. Essentially what is at issue here is that there are no hard and fast rules for the execution of the second and third pillars, thereby making enforcement nebulous and vague, effectively clouding the determination of its normative power to influence behavior.

Brunneé and Toope (2011) take an interactional view of normative development in international law. This view is built upon the premise that norms are accepted through social practice, shared understandings, adherence to specific criteria of legality (generality, non-retroactivity, clarity, etc.), and the ability of the norm to meet legal requirements. Essentially, "legal norms arise when shared normative understandings evolve to meet the criteria of legality, and become embedded in the practice of legality" (71). Taking these criteria into consideration, Brunneé and Toope direct their analysis towards the Responsibility to Protect and

${ }^{4}$ I.e. there is a lack of specific prescriptions or applications of the norm in practice. 
ultimately conclude that the norm falls short on the legality criteria of "generality, clarity, consistency, and constancy over time," and "inconsistent practice" (2011, 79). This conclusion echoes Bellamy's assertion that the second and third pillars of RtoP suffer from the problem of indeterminacy.

In The Oxford Handbook on the United Nations, José Alvarez (2009) makes the assertion that the study of international law has come to resemble the study of national law, in that it applies game theoretic and principle-agent approaches to support his claim. To Alvarez this suggests something significant about the nature of international law and its relationship to states and state authority. Alvarez believes that interaction between organs of the UN itself has helped define concepts relevant to international law; "If, for example, it is not longer acceptable for states to claim that scrutiny over how they treat their own nationals interferes with their 'sovereignty,' this has been established, at least in part, by innumerable examples of the rejection of such arguments by the General Assembly" $(2009,6)$. Though instructive and insightful, this statement may be to general or non-specific, and may not allow us to evaluate alternative reasons or motives for said rejection. It does, however, allow us to examine a possible mechanism by which norms are evaluated and legitimized in the UN and across its member states.

In his study of the assumed legal nature of RtoP, Ekkehard Strauss writes, "no new collective legal obligation has been created [by RtoP]. Instead, the responsibility offers an opportunity to improve the implementation of existing legal norms" (Strauss 2010, 25). Strauss points out that while RtoP may not be asserting a 
new international norm it may provide a mechanisms by which we may more effectively carry out and enforce the existing norms (this is addressed further in the final section on Current Perspectives). Strauss also notes in his study's conclusion that opinion juris ${ }^{5}$ may solidify the responsibility as a legal norm over time as more and more legal scholars and international legal bodies like the ICJ make rulings on its enforcement and countries believe they are obliged to enforce it. RtoP in this sense is not meant to provide a new norm, per se, but to enhance the effectiveness of preexisting laws and norms through a redefinition of what sovereignty has become (which brings with it its own set of problems as is shown later in the work).

The Commission believes they have found a norm - that is, the norm that states are not allowed to do whatever they please to and with their populations whilst hiding behind the shield of sovereignty. This norm is perhaps demonstrable to a certain degree - it can be shown by the various Conventions and Protocols that certain acts when perpetrated by states trigger certain erga omnes obligations. Erga omnes refers to an obligation that a state has towards the entire international community. The Commission then claims, "This basic consensus implies that the international community has a responsibility to act decisively when states are unwilling or unable to fulfill these basic responsibilities [emphasis mine]" (75). It would be correct to say that the ICISS in this document has successfully explained

5 "Opinio juris denotes a subjective obligation, a sense on behalf of a state that it is bound to the law in question. See ICJ Statute, Article 38(1)(b) (the custom to be applied must be 'accepted as law'). Whether the practice of a state is due to $a$ belief that it is legally obliged to do a particular act is difficult to prove objectively" (Legal Information Institute 2014). 
what the crime is and convinced us that it is, indeed, a crime according to international law. This is demonstrated by precedent on atrocities like genocide and the general evolution of sovereignty norms over time. However, they have not, as they claim, successfully convinced us what the mechanisms for preventing and/or punishing that crime should be, nor who is responsible for carrying out said measures if and when it is decided that they are necessary. They have also not been convincing that sovereignty has been successfully redefined through these normative developments, but merely that some responsibilities may exist. The Commission has certainly offered suggestions and opinions; however their assertion of the normative status of this responsibility is premature.

The international community has shown some hesitation in accepting the Responsibility to Protect as an international legal norm. This hesitance is reflected in the language of Resolutions and manner of discussion surrounding military actions and humanitarian interventions worldwide. As Bellamy notes, "a paragraph indirectly referring to RtoP was deleted from a draft of Resolution 1769 (2007) on Darfur; and Resolution 1814 (2008) on Somalia pointedly referred to the protection of civilians and Resolution 1674 without referring to RtoP" $(2010,145)$. The removal of RtoP language from resolution drafts and the purposeful avoidance of evoking RtoP imply that at least a portion of the international community wishes to avoid legitimizing and normalizing RtoP as an international legal principle. There are a number of proposed reasons for this observable behavior, which is explored more in depth throughout the work. Whatever the actual reason, observation 
strongly suggests that many nations are reluctant to see the positive normative development of RtoP or at least development of its compliance-pull.

Responsibility to Protect norms involve more than just the consideration of direct military intervention or even just the actions of states and international organizations. The association with RtoP should also be preventative diplomacy and norm adoption as opposed to military action (Bellamy 2010). Bellamy further suggests that there is a kind of constructive norm adoption occurring at the national level and with leaders that makes committing atrocities less of an option or less present for world leaders, insurgents, rebels, etc. This is partially shown by a decrease in atrocities without a decrease in atrocity-associated conflicts, i.e. the situations that historically have given rise to atrocities continue to occur, however the atrocities themselves do not, or at least occur less frequently. He also admits that it is "impossible" to draw a direct causal connection between the cooling down of atrocities in the world and the development of R2P as a norm. Despite the existence of this direct causal connection, Bellamy believes this shows "active belligerents are more often choosing not to commit atrocities" $(2010,164)$. If this is true it suggests some international actors, even if not states, are altering their behavior based on a shared expectation, thereby suggesting a level of compliancepull.

In what is perhaps a more accurate sentiment, Bellamy concludes in his 2013 paper that "the presumption of non-interference has given way to a presumption of 'non-indifference' in the face of genocide and mass atrocities" (352). This is an 
incredibly accurate way to state the effect of RtoP as a developing norm. The Responsibility to Protect may not facilitate or require action in the way that some scholars and international actors want it to, but it has definitely facilitated a culture of "non-indifference." Chesterman also refers to this concept, but in a slightly different way when he writes, "the true significance of RtoP is not in creating new rights or obligations to do 'the right thing'; rather, it is in making it harder to do the wrong thing or nothing at all” $(2011,8)$. This implies that one of RtoP's principle functions may be to punish inaction by the responsible states or international bodies as opposed to just attempting to force action by states, e.g. diplomatic pressure against indifference. Furthermore, Bellamy believes that the Libyan intervention characterizes this related norm of non-interference quite well. He writes, "Council members that remained sceptical [sic] about the use of force abstained because they believed that they could not legitimize inaction in the face of mass atrocities" (Bellamy 2011, 844). In other words, they may not themselves have felt a responsibility or obligation to act, but they also did not stop others from acting to prevent the potential abuses in Libya even though they could have exercised their use of the veto to do so. Though instructive for norm development, there is more to the Libyan intervention than meets the eye, as is shown in Chapter 3.

The function of human rights as a policy tool in the Security Council during the Cold War is instructive for looking at the current path of RtoP as a policy tool in the United Nations. The decade following the Universal Declaration and Convention on the Prevention of Punishment of the Crime of Genocide illustrates the difficulty of 
adopting a norm like human rights in an environment consumed by security and ideological differences (Luck 2011). The comparative environment provides important contextual clues as to the status of norm generation in general, i.e. that norms develop most quickly in a world where primary security objectives are not present. From a realist perspective this implies that humanitarian norms like the Responsibility to Protect are secondary objectives for states. This is explored more fully in the second chapter.

The United Nations has a legitimating influence on policies and norms. Barnett and Finnemore claim, "[UN action] can legitimate policies [...] create and diffuse international norms, policies, and models of political organization around the globe" $(2009,2)$. Oddly enough some scholars believe that the legitimating influence of the United Nations could potentially serve as a barrier to multilateral action in some cases. Alvarez (2009) implies that this legitimating power may present a barrier to multilateral policy in the potential circumstance that if the parties involved do not wish for their actions to be advanced as a legitimate norm they may work outside of the UN to prevent such normalization. This may also lead to pseudo-intervention (Thakur 2009) wherein the traditional norms like selfdefense and threats to international peace and security are referenced as justification for intervention as opposed to the humanitarian crisis. These pseudointerventions may or may not be an effort to keep from legitimating the norm, or they may be an attempt to maintain its legitimacy by not applying it too widely. 
It is relatively safe to say that the entirety of the Responsibility to Protect is not considered to be a norm that necessitates or requires certain behaviors or responses. There are portions of the ICISS report that have found a measure of widespread acceptance, such as the concept that sovereignty does not entail absolute power to do as one wishes, including committing genocide, with their own population. This partial acceptance makes assessing the path of RtoP's normative development a difficult task. How RtoP is applied in present and future cases, and how it develops in the United Nations will go a long way towards revealing this development over time.

\section{Chapter 2: Central Issues Explored}

\section{Introduction}

This chapter examines the central issues of the Responsibility to Protect as they relate to the moral and legal facets, as well as other practical effects of its adoption as an international legal norm and its applications. The status of the Responsibility to Protect as a legal norm is still under question and up for review. The uncertain nature of RtoP is due to a number of issues involved in its conceptualization and implementation. The central contentious issues surrounding the concept of the Responsibility to Protect and its adoption as an international legal norm are related largely to authority, legality, effectiveness and morality specifically the assertion of value systems and the redefinition of sovereignty. These issues are addressed briefly in this introduction to provide context and expanded 
upon subsequently in more depth throughout the study conducted here. Briefly, these issues are norm conflict, indeterminacy, prevention, the redefinition of sovereignty, the Security Council's legitimacy, the distinction between obligation and permission, the potential abuse of intervention, and reconciling political will and state interests. The theoretical foundation established in the previous chapter allows us to address the practical and legal issues inherent in the potential enforcement and adoption of the Responsibility to Protect.

The legal issues surrounding RtoP are fairly clear and straightforward. Essentially, the controversy surrounds the norm conflict between sovereignty and intervention. Sovereignty is a well-established norm in international law and the foundation of the nation-state international system in which we currently find ourselves. Part of sovereignty has traditionally been the norm of non-intervention in essentially domestic affairs, a concept enshrined in Article 2 (7) of the UN Charter. The Responsibility to Protect is asserting its propositions about the justified use of force for humanitarian intervention by redefining or altering the established sovereignty norms which the ICISS believes have changed over time enough to justify this alteration. This in turn creates a conflict between the norms that is difficult to reconcile. Related to this is the authority issue, i.e. who or what international body is responsible for determining whether or not these interventions are legitimate, and is that organization itself a legitimate authority to make such a determination? 
Practically, RtoP suffers from the issues of indeterminate mechanisms for its enforcement, including prevention, and effective enforcement. The triggers for intervention are not well-established or particularly well-defined, nor are the mechanisms for prevention and rebuilding. Furthermore, it may be physically difficult to enforce prevention, reaction, and rebuilding with the right amount of man power and boots on the ground. These practical considerations make it difficult to move RtoP from the realm of theory to actual practice. The resolution of these issues is required if RtoP is to become an effective norm enforceable by the international community.

The moral issues surrounding RtoP are somewhat less straightforward than the legal ones. There are moral implications embedded in the assertion of RtoP's protective human rights principles, and particularly so in the prevention principle of RtoP - this issue is informed largely by the discussion on Theoretical Foundations in the previous chapter. The fundamental motivating agent of RtoP is the assertion of universal principles of human rights and, to a lesser but very real extent, democratic and Western value systems. Intervention in the sovereign affairs of other nations not only has legal implications, but moral ones as well. Such interventions imply the hierarchical ordering of value systems and types of government. The assertion of cosmopolitan ideals is found strongly in the ICISS report and the mechanisms for prevention. Again, part of the objective of this work is to shine a light on the mechanisms by which concepts that are generally considered to be "good" operate and determine whether those mechanisms are equally good by a subjective 
measure. The discussion of the moral issues of RtoP is meant to accomplish this end. The discussion on morality here, as opposed to the theoretical discussion of morality in the previous chapter, is conducted by making direct reference to the countries and peoples being affected by RtoP as opposed to more general theorizing about the source of morality in international society.

Ultimately, the Responsibility to Protect is "dependent on the dominance of particular ethical viewpoints" (Morris 2013, 1278), i.e. the Kantian, cosmopolitan view of the source of rights and upon whom rights are conferred and to what degree. The discussion of RtoP takes place in this context but recognizes that the moral or ethical landscape of the international system may not always appear as it does today. The following exploration of the central issues of RtoP takes for granted that the international system is dominated primarily by powerful, Western democracies and attempts to highlight the struggle between these democracies and the rest of the world as it is represented by the RtoP norm.

\section{Norm Conflict}

Much of the controversy around RtoP can be summarized in terms of norm conflict (Vranes 2006). In essence, RtoP asserts or creates international legal norms that conflict with existing norms. As explored previously, the Commission has asserted that the concept of sovereignty has changed or evolved, however this has not been empirically proven, merely stated. The sovereignty norm has a longstanding history, the essentials of which are provided in the first chapter, and the redefinition of it puts RtoP into conflict not only with the sovereignty norms but 
other interrelated norms. The following section explores this conflict between norms.

The tension between norms within the United Nations is relatively clear. Ramesh Thakur writes, "the controversy over humanitarian intervention arises from a conflict between different contemporary norms, producing normative incoherence, inconsistency, and contestation." Thakur also states that this inherent tension exists within the United Nations Charter itself, as well, and is characterized by "inherent tension between the intervention-proscribing principle of state sovereignty and the intervention-prescribing principle of human rights" (2009: 2, 8). In part, the Commission attempts to reconcile or avoid this conflict between sovereignty and intervention by trying to redefine sovereignty as opposed to openly challenging it with another norm.

It is also useful here to attempt to explain what norms are meant to do in order to understand how they are in conflict. Erich Vranes writes, "Norms have the fundamental functions of obligating, prohibiting and permitting, according to deontic (legal) logic" $(2006,398)$. The Responsibility to Protect permits and perhaps obligates (depending on the crime committed and who makes the decision). Sovereignty mostly just prohibits certain behaviors from the outside, i.e. the international community is prohibited from interfering in matters that are under the direct sovereign jurisdiction of a state. Both norms claim to explain the same concept or conceptual framework and define it in mutually exclusive ways. Perhaps more accurately, RtoP attempts to replace the traditional definition of sovereignty 
with its own. The traditional norm of sovereignty is undoubtedly mutually exclusive in its permissions and prohibitions with the RtoP norm, thereby signaling a norm conflict. According to the definitions provided by Vranes this is a contradictory conflict between permission and prohibition. If attaining the regulation of behavior in the international system is impaired by a permission incompatible with a prohibition (i.e. you may and you may not), or a permission inconsistent with an obligation (you may, but you must), these norms are by definition in conflict. This does not mean, however, that both norms cannot exist at the same time even in the case of their mutual exclusivity; "a norm conflict is not a logical contradiction and cannot even be compared to a logical contradiction', as it is perfectly possible for two conflicting norms to occur within one and the same legal system" (Vranes 2006, 399). From this we can draw the conclusion that the norm conflict exists, however this recognition does not help us to reconcile the simultaneous existence of both norms. Indeed, it is the very fact that they exist simultaneously within the same system that is ultimately problematic. Even by a "broader" definition of norm conflict RtoP creates controversy. According to this broader definition, "There is a conflict between norms, one of which may be permissive, if in obeying or applying one norm, the other norm is necessarily or potentially violated" (Vranes 2006, 418). Obeying or applying the Responsibility to Protect essentially requires the sovereignty norm be violated. Again, the Commission attempts to redefine this norm in order to avoid the conflict and reframe the argument. As explored later, this 
violation can even take the form of activities below the threshold of outright military intervention.

With respect to the Just War triggers for intervention discussed in the Defining section in Chapter 1, the Commission provides a number of situations that would satisfy the just cause requirement for intervention. The first four examples provided are already covered by international treaties ${ }^{6}$. The second two, however, are less explicitly legal with respect to international legal precedent, and rely much more heavily upon the redefinition of sovereignty as responsibility outlined in the document. One is "state collapse" that results in civil war, etc., and the other is "overwhelming natural or environmental catastrophes" (ICISS 2001, 33). The relative lack of solid precedent makes these assertions slightly more dubious, especially the civil war example. Enforcing R2P in the case of state collapse leading to a civil war is in direct conflict not only with sovereignty norms, but the norm of self-determination as well. C. A. J. Coady draws parallels with the American Civil War to illustrate the hypocrisy and indeterminacy of some of the central RtoP tenets. Coady writes;

The ghastly horrors of the American Civil War might have presented a case for humane military intervention by outsiders, but as William Shawcross put it: "If the prospect of having their conflict 'managed' for them by foreigners (however well intentioned) would have been unwelcome to the American people then, why should it be more acceptable to other peoples in the world today just because the motives of those who believe fervently that 'something must be done' are often decent?" This indicates that the value of self-government is connected to some form of sovereignty, and this in turn

${ }^{6}$ The 1948 Genocide Convention, large scale loss of life, ethnic cleansing, systematic killing, acts of terror, systematic rape, and the Geneva Conventions and Additional Protocols (ICISS 2001, 33). 
should caution against any revived enthusiasm for benign imperialism

whether in the form of humane rescue or advancing democracy. $(2009,79)$

The hypocrisy of the Commission and the United Nations in general can be seen in this comparative thought exercise. The later section on the Prevention principle of RtoP further highlights the normative and subjective nature of RtoP goals and the values that it reflects. This shows that RtoP potentially and actually conflicts with many norms, not just sovereignty. These conflicts are created in part by indeterminacy and in part by inconsistent or inequitable application.

There are other norms within the Responsibility to Protect that conflict with existing norms, as well. Chris Brown writes,

We have a number of relevant moral intuitions here, but they tend to contradict one another - thus, most basically, we think peoples ought to be self-determining but we also think they ought not to do bad things to each other; we believe in human rights, but we believe that people ought not to be forced into some uniform strait-jacket, such as the one mandated by the international human rights regime, and so on. (Farer et. al. 2005, 225)

The norm conflicts presented by RtoP are numerous and difficult to reconcile. It is not only the obvious norm conflict between state sovereignty and intervention that is problematic for RtoP, but also norms regarding self-determination, use of force, aggression, preemption, and non-interference.

\section{Indeterminacy}

The precision of definitions and concepts contained within the language of the Responsibility to Protect are vital to its successful adoption. The fact of this indeterminacy has been discussed, however this section addresses the issues created by the indeterminate nature of a number of the concepts contained within 
RotP. This is essentially an issue of operational effectiveness (as opposed to authoritative effectiveness which is addressed later), i.e. in deciding precisely what should be done to stop atrocities (and by whom) rather than whether or not something should be done to stop them. This is usually referred to in terms of the second and third pillars of RtoP, i.e. international responsibility and military intervention.

In simple terms, this indeterminacy is usually illustrated by the idea that while most international actors believe that "something" should be done in the face of atrocities (Pillar I), no one can seem to agree on what that something should be (Pillars II and III). With respect to the lack of intervention in Darfur despite a fairly widespread determination that "something" should be done, De Waal writes, "very little attention was paid to the concept of operations and strategic goal. This emphasis reflects the focus and content of the continuing debate on the responsibility to protect, which has concentrated on when and whether to intervene, not how to do so and with what aim in mind" $(2007,1045)$. This highlights the effectiveness issue perfectly. Lawmakers, scholars and statesmen seem to agree that "something" should be done, however they cannot seem to agree with the same degree of ease as to what exactly should be done - this is a central issue with the RtoP concept in practice. Even if the concept itself is accepted there is a significant dearth of specific, operational literature on how to conduct the interventions. 
Even allegedly positive applications of RtoP or humanitarian interventions do not precisely address this indeterminacy issue. Bellamy writes, "while the Council's response to the crises in Côte d'Ivoire and Libya might reflect a new politics of protection, it is clearly much easier to agree on the principle that people should be protected from serious crimes than it is to agree on what to do in specific circumstances" $(2011,826)$. It seems to be relatively easy to agree that human rights abuses are objectively immoral and should be stopped, however we have fallen short on the mechanisms for determining when legitimate action should take place and, furthermore, who should be taking it and how. Much of the literature on this subject is an attempt to parse out such guidelines as they may be acceptable to those powerful states with the ability to make binding decisions, like the permanent members of the Security Council, for example. The case studies in Chapter 3 further serve to highlight the practical effects of this difficulty.

This indeterminacy issue applies also to how and when determinations that RtoP is required are made. Tom Farer (2005) and his colleagues endeavor to define or outline the requirements for classifying a situation as one that dire enough to trigger intervention obligations and/or requirements - among these requirements are usually mentioned "slaughter, systematic torture, mass detention for an indefinite period under deplorable conditions, and systematic and deep violation of minority rights," etc. The effort is an honorable and necessary one for the acceptance of RtoP. However, the futility of these definitions once again becomes clear - they are simultaneously too narrow and too broad, i.e. indeterminate. They 
also usually include among their reasoning the ever-present concept of "imminent" danger - a concept which itself lacks a clear or widely-accepted definition. Until there exists a clear, widely-accepted definition of these concepts RtoP will be continually hindered.

\section{Prevention}

The prevention principle of the Responsibility to Protect is essentially about encouraging and facilitating respect for human rights abroad in order to lower the chances of atrocities in cases of government failure, civil war, etc. Effective prevention is a "key objective" of the International Commission on Intervention and State Sovereignty. This effective prevention consists in large part of good "early warning" capabilities (effective institutional frameworks for analyzing and acting upon information), a good "preventive toolbox," and "political will” (ICISS 2001, 20). The prevention principle of RtoP is arguably its most presumptuous tenet. The issues inherent to prevention are political, moral, and ethical. This section shows that the attempts at prevention put forward by the ICISS are paternalistic, ethnocentric, and preference-based. Furthermore, the mechanisms are ill-defined and not always empirically effective. One of the questions fundamental to consider within this section is this; when does prevention cross the line into preemption?

The "early warning" capabilities, or what the ICISS calls "root cause prevention," clearly reflect democratic values and the cultural, social, and economic preferences of the First World policy makers. Along with the toolbox, these root cause prevention measures are presented as political, economic, legal, and military. 
In the realm of political prevention they state, "this might involve democratic institution and capacity building" $(2001,23)$. This may suggest that the writers of the report believe democratic institutions are the most preferred when it comes to preventing atrocities like genocide and ethnic cleansing. In reference to prevention and rebuilding periods, the Commission states,

Apart from, hopefully, removing or at least greatly ameliorating, the root causes of the original conflict and restoring a measure of good governance and economic stability, such a period may also better accustom the population to democratic institutions and processes if these had been previously missing from their country. (ICISS 2001, 44)

This statement is offered as if democratic institutions are assumed to be preferable to any other, without any qualifying statements. In this context, democracy and democratic institutions are the default, the assumed best form of government or societal organization. Whether or not this is true, it is beyond the scope of the UN to prescribe government types to nations, especially in this context - this is precisely why some countries cry neo-imperialism and are skeptical of RtoP as simply another method for large, Western countries to intervene in smaller developing nations and change their policies to be more Western. The guidelines for economic root cause prevention are incredibly comprehensive, essentially advocating for a full-scale conversion to free market capitalism:

This might involve development assistance and cooperation to address inequities in the distribution of resources or opportunities; promotion of economic growth and opportunity; better terms of trade and permitting greater access to external markets for developing economies; encouraging necessary economic and structural reform; and technical assistance for strengthening regulatory instruments and institutions. (ICISS 2001, 23) 
These economic guidelines are even more normatively expressive than the political ones. By speaking of what this prevention "might" involve, the Commission avoids saying that prevention essentially involves such reforms. However hedged these prescriptions are, they clearly reflect a certain belief system about what form of government and what form of economic system is most beneficial.

For their part the ICISS does recognize the inherent coercive nature of preventative measures. They point out that some nations fear "internationalization" of issues which may in time lead to intervention and that they may be right to fear this possibility. They offer two "answers" to this concern;

The first is for international policy makers to be sensitive to it: to recognize that many preventive measures are inherently coercive and intrusive in character, to acknowledge that frankly, and to make a very clear distinction between carrots and sticks, taking care always in the first instance to fashion measures that will be non-intrusive and sensitive to national prerogatives. But the second answer is one for the states themselves: those who wish to resist external efforts to help may well, in so doing, increase the risk of inducing increased external involvement, the application of more coercive measures, and in extreme cases, external military intervention. (ICISS 2001, 25)

The above is a rather puzzling paragraph from the Commission's report. The first answer rightly acknowledges that the countries being interfered with, at least potentially, have a right to be concerned about intervention and that preventive efforts should keep these concerns in mind. The second answer implies that states should be concerned about being intervened with, because if they do not cooperate with prevention efforts then they are potentially bringing more intervention and intrusion upon themselves. This statement seems much more threatening than it does explanatory or empathetic to the cultural and political sensitivities of 
intervention - it reads more as a warning than an assurance. It also implies, as does the general language of prevention, that some manner of "guilt" has been preestablished and judgment passed on a number of aspects ranging from political to economic. This may be where we cross the line from prevention to preemption. This is partly a reflection of the indeterminacy problem, i.e. how a nation is determined to be "at risk" and therefore require this root cause prevention. On the whole there is an implication of superiority - an implication that the United Nations knows what is best for its member nations who exhibit "risk factors" for atrocities. Essentially, “This form of preventive intervention would institute comprehensive Western regulation under the threat of military intervention if non-Western states were 'unwilling or unable to cooperate'” (Chandler 2004, 67). The fact that the triggers are so woefully indeterminate makes the assertions contained within the language of prevention that much more problematic.

Even the most non-intrusive of prevention efforts may be seen by some nations as a violation of sovereignty. As Bellamy (2010) notes, in the discussions of RtoP following the 2005 Outcome Document, "Several member states worried that information gathering and assessment by the UN violates sovereignty and can be easily politicized" (148). The concern here being that the UN may make a determination that this root cause prevention is required and the potentially offending nation is forced to comply with surveillance and assessment measures or face negative political consequences in spite of the fact that an infraction has yet to take place, or perhaps never will. These concerns imply that prevention can be a 
violation of sovereignty norms by itself even before actual military intervention. Edward Luck agrees that "some aspects of structural prevention could be quite intrusive, just as are international development and peacebuilding programmes" $(2011,11)$. Not only are these measure potentially intrusive, they also potentially threaten the social and political structures of the target nations. The liberal view of this nation-building strategy is that "aligning state prerogatives with the will and consent of the people, the ruling class of any country must now fear the risk and threat of international economic, criminal justice and military action if they [...] cross UN red lines of behaviour" (Weiss et. al. 2011, 14). The preceding statement by Ramesh Thakur is emblematic of the liberal approaches to the spread and enforcement of RtoP in a democratic context.

Prevention relates to the indeterminacy issue as well, i.e. when are preventative measures triggered? As the Commission states, "military intervention for human protection purposes should be restricted exclusively, here as elsewhere, to those situations where large scale loss of civilian life or ethnic cleansing is threatened or taking place" (ICISS 2001, 34). This places RtoP in a very exclusive and specific category with a broader goal, i.e. protecting civilians. For example; even though the overthrow of a democratic regime by military coup may theoretically lead to large scale loss of civilian life, it does not necessarily lead to such, at least insofar as the Just War triggers for RtoP are concerned. The purview of RtoP is therefore dependent on the loss of life variable, and not to those things that may lead to it. It is the job of the prevention portion of RtoP to support and maintain 
good relations with democratic regimes to potentially keep coups from happening or perhaps be able to administer aid swiftly in the event that such aid is required. The distinction between what does in fact and what may in theory lead to atrocities is an important one that highlights the difficult nature of prevention.

These difficulties are heightened by the relatively non-empirical way in which the necessity for preventative measures can be interpreted. In their Supplementary Volume to their full 2001 report the ICISS writes;

Too heavy an emphasis on structural causes of conflict is also empirically inaccurate - social inequities and resource scarcity do not in fact always lead to deadly conflict, and they can in some instances produce healthy nonviolent conflict that catalyzes positive social change. Protests in democratic societies are an obvious example, but even armed struggle for self-determination against a repressive regime may remain within acceptable bounds of violence (ICISS 2001a, 32)

Though not contained in the main report, this supplementary caveat highlights the operational issues inherent in attempting to carry out prevention effectively in a legitimate way. It is not well-known what preventative efforts have a proven causal relationship with a decline in the committing of atrocities, therefore prescribing certain measures before any real guilt has even been determined is premature, to say the least. As the case studies in the subsequent chapter show the question of what level of violence is acceptable is not uniformly applied in each case.

The stated goal of prevention, to prevent the occurrence of atrocities like genocide and ethnic cleansing, is an admirable and desirable one. However, the mechanisms for achieving that end are woefully inaccurate, terribly restrictive and ethnocentric, essentially establishing guilt prior to any crimes. The establishment of 
this guilt potentially opens the door for full-scale conversion to Western democracy and free-market capitalism, institutional arrangements that are supposed to prevent atrocities according to the Commission but without showing an actual causal relationship. The advancement of these structures reflects the interests of the privileged and powerful nations making and enforcing the policies on an international level. Prevention may effectively amount to threat diplomacy in a practical sense. Applying prevention presents a wide array of issues for RtoP.

\section{The Redefinition of Sovereignty}

One of the central propositions contained in the 2001 ICISS document is its redefinition of sovereignty - it is also one of its most contentious propositions. Sovereignty is an age-old concept with centuries of precedent and most if not all nations still adhere to it internally and externally. The ICISS and others have asserted that the concept of what sovereignty entails and the freedoms or prohibitions it permits has changed enough since the establishment of the United Nations that it requires redefinition. This section explores the claims made by the Commission with respect to sovereignty in juxtaposition to the traditional concept of sovereignty presented in Chapter 1 . As a central tenet of RtoP, understanding the effects of this redefinition is of the utmost importance.

Since we have already explored the traditional definitions of sovereignty in Chapter 1, this section focuses more on the legality and legitimacy issues presented by such a redefinition. The prevailing literature on RtoP suggests that there are further characteristics of sovereignty than this included in the traditional 
Westphalian characteristics. Weiss claims, "In addition to the usual attributes of a sovereign states that students encounter in international relations and law courses in the 1934 Montevideo Convention - people, authority, territory, and independence - there is another: a modicum of respect for human rights" (Weiss et. al. 2011, 9). The Responsibility to Protect asserts that this respect for human rights has become part of the definition of sovereignty and their proceeding argument is based upon this assumption.

Kant wrote that clinging to sovereignty facilitates a kind of "state of nature" existence that Hobbes explores in Leviathan (1651) on the international level, wherein states are free to do as they wish without limit within their own borders. In the Kantian sense, "Only savages would want to cling to their lawless freedom - 'we regard this as barbarism, coarseness, and brutish debasement of humanity'" (Brown 1992, 36). Furthermore, this conception of the state of nature in international law implies that force determines legality, which for Kant would be a "meaningless abomination" (Brown 1992, 37). In this sense sovereignty is a shield that nations may hide behind while they commit crimes against humanity within their own borders. Kant and the ICISS want to say that international society is responsible for preventing these atrocities, and that sovereignty in and of itself is not a valid defense to keep the international community from doing so.

The definition of sovereignty as it stands currently is essential to the operation of the RtoP principle and its potential acceptance as a norm, seeing as the principle relies on a reexamination or redefinition of sovereignty in order to 
function. In light of the heretofore-examined definitions of sovereignty and their substantial precedent, we come now to the definition of sovereignty as it is contained in the premier RtoP document, the 2001 report from the International Commission on Intervention and State Sovereignty. Somewhat perplexingly, the ICISS document (2001) makes its argument for the redefinition of sovereignty in a relatively very short five paragraphs, the most central of which is worth quoting in its entirety;

1.35 The defence of state sovereignty, by even its strongest supporters, does not include any claim of the unlimited power of a state to do what it wants to its own people. The Commission heard no such claim at any stage during our worldwide consultations. It is acknowledged that sovereignty implies a dual responsibility: externally - to respect the sovereignty of other states, and internally, to respect the dignity and basic rights of all the people within the state. In international human rights covenants, in UN practice, and in state practice itself, sovereignty is now understood as embracing this dual responsibility. Sovereignty as responsibility has become the minimum content of good international citizenship. (8)

In the above paragraph taken from the document in question, the ICISS has essentially presupposed that their goal has come to pass, i.e. the widespread acceptance of their redefinition of sovereignty as responsibility and all of the responsibilities that concept confers upon nation-state and their leaders.

The ICISS report takes for granted that the responsibility to protect exists and then builds their argument upon that assumption. Welsh and Banda point out the problematic nature of this kind of argument; "The [ICISS] Commissioners spent the bulk of their time outlining the conditions under which the principle of nonintervention may be overridden in the name of protecting human rights, and less time answering the fundamental question of why there is a prospective 
international responsibility to protect" $(2011,123)$. The Commission presumes the outcome that they want and then builds their argument upon it, as if to make us ask ourselves how we could have ever denied such a thing, all without really convincing us that it is true in the first place.

The concept of the apparent erosion of sovereignty as a legal principle is also referenced by a number of international legal scholars. Ramesh Thakur asserts, "The gradual erosion of the once sacrosanct principle of national sovereignty is rooted today in the reality of global interdependence" $(2009,11)$. The possible role that interdependence plays in the sovereignty arguments is highlighted in the discussion of globalization provided by the ICISS. In their 2001 report they assert, "In reality, what is happening is a convulsive process of state fragmentation and state formation that is transforming the international order itself. Moreover, the rich world is deeply implicated in the process. Civil conflicts are fuelled by arms and monetary transfers that originate in the developed world" (ICISS 2001, 5). This sentiment is echoed by Neta Crawford in the 2005 Roundtable discussion on humanitarian intervention after 9/11 when they write, "we ought to be more frank about just exactly what it is that we are already doing to make the lives of others more miserable or less miserable. What kinds of daily acts of intervention do we practice, and to what effect" (Farer et. al. 2005, 232)? Crawford and the ICISS are arguing that globalization negates the sovereignty norm in a way, in that we in the prosperous West are already intervening in a myriad of different ways on a daily 
basis across the globe, however we use sovereignty as a shield when it comes to responsibility to halt abuses. The point is well taken.

Perhaps the most difficult issue with the redefinition of sovereignty as responsibility is a conceptual one. The redefinition of sovereignty is based upon the assumption that an unspecified yet sufficient number of states have developed values and practices similar to those held by the Western nations in order to make them common practice, i.e. the shared expectation. The concept is thereby raised up to a universal, cosmopolitan level. The universal approach states that all humans are or should be afforded the same basic human rights insofar as the concept has developed in international law. The concept itself is inherently and fundamentally universal, hence the cosmopolitan theoretical perspective. This allows the logic of multilateral humanitarian intervention to work, but that logic also requires that the preceding assertion is indeed true. Even if the presence of a normative change could be demonstrated, it may or may not be morally or ethically correct just because it is a norm. Once R2P ascends to the level of an enforced international law (or perhaps even a lower threshold such as normative acceptance), assuming it ever does, does it automatically become morally justified? Do the norms, values, and practices contained therein become universal in practice, or did they become accepted because they are universal? What does this mean for moral relativism and the communitarian perspective? This is especially problematic because R2P rests upon the logic that these rights are universal in the first place, but they have to become accepted as a norm to hold that claim as valid. 
Alex Bellamy echoes the claims of many pro-RtoP scholars when he writes, "RtoP is universal and enduring - it applies to all states, all the time. From this perspective, there is no question of whether RtoP 'applies' to a given situation because RtoP does not arise and evaporate with circumstances" $(2010,158)$. This claim is endemic to much of the literature that advocates for RtoP. It is undoubtedly problematic, however, that RtoP assumes legitimacy in its very formulation without having proven that legitimacy.

In light of the difficulties faced by redefining a concept as important to the international system as sovereignty, one may wonder why it is that the Commission has attempted such a task. Sovereignty is the bedrock of the international system and fundamental to understanding international relations (bin Talal and Schwarz 2013). There is little chance that this 360 -year-old concept will be thrown by the wayside anytime soon, thus RtoP's insistence on redefining the concept of sovereignty as opposed to discarding it or attempting to challenge it directly. By simply changing an existing concept the Commission attempts to do away with any norm conflict. As we have seen, however, the norm conflict exists regardless of this attempt. The redefinition of sovereignty, as opposed to its abandonment, is therefore central to the success of RtoP for these reasons. This ties into one of the central assertions of the ICISS, which is that the Responsibility to Protect strengthens sovereignty as opposed to undermining it by helping nation-states in fulfilling their sovereign duties, i.e. protecting their populations from genocide and ethnic cleansing. The idea put forward by RtoP proponents is that RtoP is 
strengthening sovereignty by "helping States to meet their core protection responsibilities" (Deller 2012, 67). It is difficult to understand how one strengthens sovereignty by interfering in essentially sovereign affairs within the sovereign jurisdiction of states. If RtoP is doing anything, it is strengthening the concept of sovereignty that has been redefined and represented as fact by the SecretaryGeneral and other RtoP proponents, but certainly not the traditional definition of sovereignty. It is strengthening $a$ definition of sovereignty, but not the definition.

The concerns of some developing nations are that rather than strengthening sovereignty as the Commission claims RtoP undermines sovereignty by opening the door for a pattern of intervention in developing countries who do not have the military capability to defend themselves and who may have value systems and governments different from the interveners. Furthermore, some nations are concerned about their comparatively limited role in the decision making process of the authoritative body for RtoP, the United Nations Security Council. Weiss believes that these reservations are summarized in part by Algerian President Abdelazia Bouteflika:

We do not deny that the United Nations has the right and the duty to help suffering humanity, but we remain extremely sensitive to any undermining of our sovereignty, not only because sovereignty is our last defense against the rules of an unequal world, but because we are not taking part in the decision-making process of the Security Council. (Weiss 2004, 145)

This quotation suggests that the very countries whose sovereignty RtoP purports to strengthen may see RtoP as a tool that weakens sovereignty. The above quote also 
highlights another important issue with respect to the role of the Security Council as the ultimate authority when seeking approval for intervention.

Great powers are essentially immune to the same external responsibilities that bind smaller powers with the redefinition of sovereignty. Furthermore, as is shown in the following section, coercive action or even simply the determination of violations against any permanent member of the United Nations Security Council would be, in a word, impossible. In this respect, the Responsibility to Protect only applies to nations who do not have the power to protect themselves from outside interference. It is only the traditional concept of sovereignty that potentially protects small nations from this kind of interference. Legally, this essentially means that there is no "fair" way to apply RtoP concepts and carry out interventions that still respects sovereignty.

\section{The Security Council}

The central authority question regarding the implementation of the Responsibility to Protect is; who or what body or nation has the authority and legitimacy to authorize an intervention based on RtoP principles? Furthermore, when might a body besides the legitimate one make a determination outside of it and still have it be legitimate? This section explores that legitimate authority, the Security Council, and analyzes just how legitimate that authority is, some of its challenges, and some of the issues created by the adoption of the Responsibility to Protect. This includes some discussion of the legitimacy issues created by the veto 
held by the Permanent Five members of the Security Council (P5) and some of the opinions on possible reforms.

The lion's share of the literature on RtoP asserts that the only legitimate body to make determinations on the enforcement of the Responsibility to Protect is the United Nations Security Council (Bellamy 2005, Weiss 2004, ICISS 2001). The 2001 ICISS Document states that the Security Council is the most "appropriate" body for authorizing military interventions for RtoP (XII). The UN is not only the enforcer, but also the primary legitimating body of new international norms; ergo it is in the interest of R2P proponents to foster application of the new norm within the United Nations and by the Security Council. If it is not now a norm it may become one through continued application by the UN as a legitimate body of international law. The United Nations has become the primary legitimate decision-making body for international law, even though that was never the original intention of the charter (Alvarez 2009). From this we can infer that the United Nations and by definition the Security Council is widely considered to be the legitimate organization through which RtoP is enforced.

If the United Nations does exist as some kind of Kantian cosmopolitan ideal, then the UN itself may be an agent of moral legitimacy and action. Brown writes, "Kantian ethics are agent-centered; they impose duties upon individuals and these duties cannot be displaced to social structures -- although such structures may also be agents" $(1992,52)$. The United Nations as a focal point allows individuals as agents to assert their moral conceptions in line with Kant's "universal kingdom of 
ends," and in doing so the organization itself becomes an agent as it continues to embody the will of the individuals and nation-states that make it up. Ian Hurd defines legitimacy as "an actor's normative belief that a rule or institution ought to be obeyed," and notes that "its presence changes the strategic calculation made by actors about how to respond to the institution." Furthermore, Hurd breaks down the perception of legitimacy, which can be extended to enhance the institution, into three contributing factors; favorable outcomes, fairness, and correct procedure (2007: 7, 30, 67).

In spite of the arguments for Security Council legitimacy and the apparent general acceptance of the Security Council answer to the authority question, there are also a number of researchers and legal scholars who believe that there should be a way to circumvent the Security Council in the case where there is a deadlock caused by the use of vetoes by any of the Permanent Five members of the Council, but where intervention-triggering violations are nonetheless occurring (ICISS 2001). The study of Kosovo in Chapter 3 illustrates this difficulty. This concept is also built into the ICISS Document's definition of the Responsibility to Protect. The opening outline of the document under the section titled "Right Authority" asks that the Security Council agree to not use the veto in cases of humanitarian intervention, and that the General Assembly should consider the use of the Uniting for Peace Resolution in situations of Council deadlock due to use of the veto.

Use of the veto is not only a practical obstacle but a political one as well, with countries like Algeria feeling there is a democratic deficit in the Council that may 
threaten the legitimacy of their determinations. The ICISS recognized this in their 2001 document; "Many of our interlocutors regarded capricious use of the veto, or threat of its use, as likely to be the principal obstacle to effective international action in cases where quick and decisive action is needed to stop or avert a significant humanitarian crisis" (51). There is a significant amount of scholarly literature on the various ways in which Security Council legitimacy may be enhanced. Most of this literature involves some manner of Security Council reform, whether that be expansion of the Security Council (Hoffman and Ariyoruk 2005), reform or abolition of the veto (Weiss 2003, Fassbender 2003), or some other kind of intermediate reform that is a combination of the two or gives some limited concessions with promises of more reform at a later date (Martini 2009). The possibility of Security Council reform is somewhat mixed among the literature, but generally considered to be unlikely, especially with regards to the P5 veto power. Weiss and Young's research suggests that two thirds of the academic community believes that reform is possible, albeit within the next three, or more than five years. According to the same data, however, a high percentage of UN officials do not believe that reform is possible (2005, 134, fig.1). Weiss writes in the same 2005 paper, "there is no chance that the P-5 will ever agree to altering the veto" (132). This seems to be the general sentiment, especially considering that all of the proposals that have attempted this are vehemently opposed by the P5.

It is not only the veto problem that represents obstacles for Security Council legitimacy. Critical Legal Theory scholars believe that mainstream international 
relations and international law are promoting Western ideology and ignoring the "deployment of power" when determining the legitimacy and morality of norms (Alvarez 2009, 19). This is partially shown in how rogue nations are labeled and dealt with, for example, and provides an interesting lens through which to view the development of RtoP and legitimacy of the Security Council. The veto and the implied democratic deficit within the Security Council cast doubts upon the conclusions and laws reached therein. In the Oxford Handbook, Alvarez writes,

The ability of powerful states to manipulate who gets to participate in institutional lawmaking and to what end-as through "forum shifting" [...] selective condemnations of "rogue" states, or unequal access to or participation in institutionalized dispute resolution-casts doubt on whether the new conception of sovereignty as "status" or of compliance as "socialization" really constitutes progress or "progressive development." (2223)

The least powerful nations who are most at risk of having their sovereignty violated by RtoP have the least amount of say in the Security Council. This in turn creates problems for the legitimacy of RtoP and the Council itself. From a practical and realist perspective, "powerful states are much more likely to avoid being labelled perpetrators of RtoP crimes, in a manner that makes them liable for the adoption of extraordinary measures against them," and they are more likely to "get away with" norm-violating behavior (Bellamy 2013, 342). The legitimacy problems created by this assertion are staggering - how can a body be legitimate when it cannot itself be bound in the same way by the rules it enforces? This may work for a national government's monopoly on coercion, however the United Nations ideally operates on the principle of the equality of its members (Fisher 2008). 
Furthermore, as previously noted, RtoP relies on the dominance of particular ethical viewpoints to function; therefore the power dynamics of the veto-wielding members of the Permanent Five members of the Security Council are important for understanding RtoP development. As Morris notes, “A realignment in global power in favour of those normatively predisposed towards sovereign rather than individual rights is likely, therefore, to augur badly for R2P" $(2013,1279)$. This possibility extends outside of the Security Council, as well. Russia and China in particular have expressed a preference for the norm of non-intervention on a number of occasions, or at least distaste for its potential erosion (Bellamy 2011a). Regarding the Libyan intervention, Morris notes, “China, declaring itself to be 'always against the use of force', shared India's latter anxiety, as did Russia, which perceived a 'morphing' of the pro-interventionary position into something which could 'potentially open the door to large-scale military intervention'” $(2013,1272)$. This stance is characteristic of Russia and China's stances on intervention throughout recent history.

The discussion regarding the veto and Security Council legitimacy highlights one of the central normative conflicts of RtoP, which is that the Security Council is the legitimate authority for authorizing interventions, yet there needs to be a way to circumvent that authority because the determination that intervention is required or justified has already been made outside of the legitimate decision-making body. This issue is also practically related to the problems inherent in the application of prevention and establishment of guilt. When looked at in this context it is clear that 
intervention has been determined to be justified a priori, and its acceptance by the Council is merely a bureaucratic issue or formality, i.e. it is a foregone conclusion. RtoP has built into it a number of potential mechanisms to subvert the Council, while at the same time the document and other international relations scholars state that the Council is the most appropriate forum for deciding severity, authorizing military intervention, etc. These safety measures are understandable, yet admittedly difficult to reconcile. How can the Security Council be the legitimate authority on the issue when plans for subverting that authority are being made in the same breath?

According to David Chandler it is the cosmopolitan character of the redefinition of sovereignty that is at fault because it, "enables the Commission to come up with a set of moral criteria for military intervention which are held to exist independently of international law or any particular political decision or consensus in the Security Council" $(2004,69)$. The legitimacy of RtoP intervention is a foregone conclusion in this context because the norm claims to be universal and externalizes internal sovereignty. Bridging the gap between the determination to act and actually acting proves to be difficult. This highlights the legal issues inherent in applying a Universalist, cosmopolitan norm like RtoP.

The Security Council authority issue is problematic conceptually, i.e. in that the determination that a given intervention is justified has already been predetermined before the decision reaches the Council. In this light the issue becomes a battle between legitimacy, authority and effectiveness. Achieving 
consensus is a legitimacy and authority issue. However, there remains the potential problem that it will not be possible to achieve consensus within the Security Council, or perhaps even within the General Assembly, which is the fear expressed by the ICISS. But because the decision that an intervention should take place has already been determined prior to reaching the Council, this creates an effectiveness issue. Essentially, responsibility cascades down until there is not even enough power left to enact anything even in the case of consensus, and by the time it filters down far enough to achieve consensus, there is not enough power or legitimacy held by those in agreement to act effectively. Chesterman quotes Jennifer Welsh as saying, "the disjunction between stated political objectives and available military means would have Clausewitz turning in his grave" $(2011,10)$. Though admittedly glib, this entertaining comment highlights the problematic divide presented by RtoP between authority and effectiveness.

The Commission refers to this problem in their discussion of the precautionary principle of reasonable prospects;

Application of this precautionary principle [reasonable prospects] would on purely utilitarian grounds be likely to preclude military action against any one of the five permanent members of the Security Council even if all the other conditions for intervention described here were met. [...] This raises again the question of double standards - but the Commission's position here, as elsewhere, is simply this: the reality that interventions may not be able to be mounted in every case where there is justification for doing so, is no reason for them not to be mounted in any case. (ICISS 2001, 37)

While the Commission openly admits the somewhat unfair nature of the concept in principle, they do highlight the problematic nature of the issue. If the Responsibility to Protect cannot be applied fairly within the governing body for its enforcement, 
perhaps it should not be applied at all, or a different rule should be formulated. This also highlights the other issue discussed in this section, which is that the Commission and the General Assembly automatically assume the acceptance and legitimacy of the concept as a norm. To them RtoP is already a norm, and therefore we must apply it if we can - its acceptance is assured. The Commission is essentially saying that the end goal of what RtoP hopes to accomplish is worth the issues inherent in its practical application, i.e. Security Council legitimacy.

The Commission recognizes this difficulty and offers in their conclusion the consideration that if the Council allows action outside of the UN that finds favor politically among international actors, then that action threatens the legitimacy of the UN itself. It therefore behooves the Council to prevent that from happening by making intervention a priority for them. This caution by the ICISS is an attempt to make it a vital interest for the Council to make RtoP a priority and pursue its normalization. Their approach takes into consideration the power dynamics of the UN, i.e. suggesting that a loss of collective power (perhaps through a loss of legitimacy) may occur in cases of UNSC inaction, wherein states find it more beneficial and acceptable to act outside of it as they did in the Kosovo intervention. Bardo Fassbender makes particular note of this consideration: "the price that members of the international community will have to pay for their prolonged neglect of, and indifference to, the future of the Security Council and the international security system built around it, may be much higher than they seem to imagine today" $(2003,217)$. Fassbender worries that a decrease in the legitimacy of 
the Security Council over a long period of time, caused in large part by the neglect of its members, may eventually render the Council irrelevant.

The General Assembly in In Larger Freedom (2005a) states, “The task is not to find alternatives to the Security Council as a source of authority but to make it work better" (33). There are those skeptical of RtoP who claim that the Security Council must undergo some kind of a reform before RtoP is accepted by the international community (Deller 2012). Weiss (2004) among others, does not believe that this reform is possible. This leaves the General Assembly and the ICISS in a tough position with regards to establishing a legitimate authority for making RtoP determinations. If the United Nations is to be the legitimate body for determining and enforcing the Responsibility to Protect is must itself have legitimacy.

\section{Obligation or Permission}

There is some question as to whether the Responsibility to Protect triggers an obligation to the international community to act to halt abuses, or if it merely permits the international community to intervene. The distinction between permission and obligation is an important one to make for the purposes of advancing our understanding of RtoP. There are undoubtedly some international norms that, when violated, trigger an international obligation to react, i.e. an erga omnes obligation that implies universal jurisdiction for punishing the crime. These are known as jus cogens violations. The most notable of these norms is the Convention against genocide established after the atrocities committed during 
World War II. The central logic of this obligation is that genocide is so abhorrent that allowing it to occur flies in the face of everything that modern society stands for. Clear cases of genocide may still be the only situations that trigger such an obligation7 . With regards to offenses "less shocking" than genocide that RtoP wishes to encompass, i.e. ethnic cleansing and war crimes, Thomas Weiss posits, "there is no legal and certainly no political obligation to act, but at most a moral one" (Farer et. al. 2005, 235). It may come to pass, however, that the norm continues to develop into one that obligates states to act. Steven Groves (2011) worries that if RtoP ever obtains the status of binding international customary law, then its principles may be considered obligatory rather than permissive or voluntary, which would restrict the military and diplomatic sovereignty and autonomy of the United States.

The question of obligation is not only important in deciphering the normative status of RtoP, but necessary to establish what kind of effect the responsibility has on state behavior. The question is whether or not states are now "burdened with the responsibility to take action" (Strauss 2010, 51). Furthermore, does this burden carry with it any penalties for inaction, much like the duty to rescue laws sometimes found in domestic legal systems? As Stahn asks, "what if states or international authorities do not live up to their residual responsibility to protect? Should such omissions equally be subject to some sanction; and, if so, how

7 The Convention on the Prevention and Punishment of the Crime of Genocide Article I states, "The Contracting Parties confirm that genocide, whether committed in time of peace or in time of war, is a crime under international law which they undertake to prevent and to punish" (U. N. General Assembly 1948, 174). 
should they be remedied" $(2007,117)$ ? The essential question here is that if the international community has an obligation to step in to enforce RtoP (whether or not they do is as yet in question), assuming that all the just war criteria have been met and it is determined by a legitimate international body like the $\mathrm{UN}$, what, if anything, happens when they then choose not to act? In other words what are the "consequences of noncompliance" (Stahn 2007, 118)? There does not yet exist any practical answer to this question.

With respect to Pillars II and III of RtoP, Bellamy and Reike (2011) make the claim that there is legal content to pillars two and three in contrast with some of the prevailing opinions. They claim "states have a legal duty to take peaceful measures to prevent genocide wherever they have relevant influence and information and an obligation to use peaceful means to ensure compliance with the laws of war" (100). This is based on analysis of ICJ cases and ICC jurisdiction, including the 2007 ICJ case Bosnia and Herzegovina v. Serbia and Montenegro. As the aforementioned the case establishes, "the Article 1 obligation to prevent genocide requires that states 'employ all means which are reasonably available to them'”' (Bellamy et. al. 2011, 91). This is also addressed by Rosenberg (2011) in "Framework for Protection." This implies that there seems to be some development of at least a regional responsibility to protect (as well as relevant prevention measures) with real legal consequences when it comes to well-established cases like genocide, ethnic cleansing, etc., but Rosenberg reminds us that this obligation to was never expressly agreed to in the Outcome Document $(2011,192)$. 
If RtoP is indeed an obligatory norm it would suggest legal sanction in the case of inaction. However, as Strauss notes, "it is difficult to imagine how noncompliance of a political body could be practically challenged" $(2010,53)$. It would also "require an agreement on objective criteria for the establishment of manifest failure and the requirement of collective action" (53). If inaction requires punishment, we must therefore be crystal clear on which situations legally require action in this context. The section in this chapter on the indeterminacy issue of RtoP makes the legal portion of these determinations incredibly difficult to determine. The preceding analysis of the Security Council conducted here in this work also strongly suggests that there is no realistic way that punishing noncompliance by the Security Council could ever happen in a meaningful way. What this revelation brings to the discussion here is allowing us to explore how much this may hurt or hinder the legitimacy of RtoP and how difficult it is to elucidate it as a legal concept. Not only would it be ineffective to act against any Security Council member by using the United Nations, it would be similarly ineffective if not impossible to levy any kind of sanction against any member of the P5 in the case that they chose inaction over action. If there is no penalty for noncompliance then to what extent does the norm have force?

\section{Abusing Intervention}

A central issue of Responsibility to Protect is its potential to provide another justification for the interference of powerful states into the domestic affairs of the weak to serve other security or economic interests. There are fears that RtoP may 
be abused to justify pseudo-interventions like those carried out during the Cold War period under the guide of humanitarian intervention. In this section these concerns are explored through reference to the academic literature.

There exist real worries within the international communities, especially by developing nations, that RtoP may provide another potential tool with which powerful nations may justify military interventions. Alex Bellamy refers to this as a “Trojan horse," one that potentially, "legitimizes great power interference in the affairs of the weak" $(2010,152)$. Edward Luck (2011) agrees that the potential misuse of RtoP is still a real concern. This concern can be partially addressed by making sure that multilateralism is one of the foundations of RtoP enforcement, though there are certainly issues with that as we have seen. These concerns are not without merit, and it is the responsibility of those who support RtoP to assuage them.

International relations scholar Thomas Weiss (2004) seems to think that these concerns are somewhat overstated, and that the problem up until now has not been an overabundance of humanitarian interventions, but rather a severe lack thereof. Weiss' counterpoint to the idea that R2P will be misused is well taken. To suggest that RtoP will suddenly become as prominent so to be abused does not fit the reality of RtoP's practice or acceptance. Realist theories of international relations would tell us that powerful countries will continue to intervene unilaterally or otherwise regardless of the status of RtoP interventions if and when their vital interests are threatened. In short, it won't make a difference with respect 
to the potential abuse issue - powerful states can always find a reason to intervene. In this context the Responsibility to Protect is not providing a new policy tool to potentially intervening nations that they would not have otherwise had. As Krasner states, "the principles associated with both Westphalian and international legal sovereignty have always been violated" $(1999,24)$. If the violations are indeed inevitable then RtoP potentially provides an impetus for action to halt atrocities by effectively raising the stakes politically, even if there is a confluence of interest.

In some ways, the pro-RtoP literature attempts to reconcile this by assuming the right intentions of states, especially because there are so many vagaries and ways to abuse the principle. They do generally hedge and admit that motives may not be $100 \%$ pure, however the construction of their logical basis for the application of RtoP implies that they believe states will act in a somewhat altruistic or at least partially other-interested manner when adhering to the principles. This tendency is evidenced in Evans and Sahnoun's survey of the Just War interventions (2002). This does assume, however, that states actually want to prevent and react to human rights abuses outside their own borders.

Bellamy (2010) reminds us that a determination of a Responsibility to Protect trigger does not automatically confer legitimacy on coercive intervention. That is to say that even though RtoP could potentially act as a Trojan horse, labeling a situation as one that calls for RtoP enforcement does not always lead to intervention or legitimacy. Conversely, in his 2004 work, Weiss is reminds us that while RtoP may not be providing a new policy tool to justify unnecessary 
interventions based on the interests of a single nation, what it may do it provide a new policy option in the case of real or potentially imminent abuses. Furthermore, RtoP "has the effect of elevating certain issues above normal politics as a catalyst for decisive international action" (Bellamy 2010, 159). This can, of course, have positive and negative consequences. This not only allows intervention to be justified, it also potentially allows the Trojan horse problem to manifest itself.

\section{Political Will and State Interests}

Historically, there have been a number of humanitarian interventions carried out in situations where the humanitarian interest existed concurrently with other vital state interests. This has been referred to elsewhere as pseudo-intervention and is further illustrated by the normative development of international human right regime during the Cold War, wherein it appeared that human rights development was subordinate to other political and security concerns. Alternatively there are those who believe that the former concerns are not subordinate, but that the coincidence of interests makes interventions more likely to occur (Weiss, et. al. $2011,13)$. The focus of RtoP proponents tends to be in making RtoP a state interest vital enough to be enforced on its own without the need for these additional concurrent interests to be present. This is often referred to as the "political will" for intervention (Albright and Williamson 2013). The question then becomes; how do we engage great powers in places where they have no strategic interests? Part of the answer is to make adhering to an international norm like RtoP a strategic interest 
As Badescu and Bergholm write, "responses to conscience-shocking situations have depended on political conditions and interests at stake in the conflicts in question, as well as on the willingness and capabilities of various actors - whether international or regional organizations or individual states - to react" (289). This is shown in part by the lack of action in certain situations which (the argument could be made) qualify for RtoP intervention, i.e. Darfur, North Korea, etc. Lack of political will shows the limitations of the norm as a vital state interest. Alex Bellamy's 2013 article leads to some useful conclusions after collecting data on the coincidence of atrocities, calls for RtoP, and Security Council resolutions; 


\begin{tabular}{|c|c|c|c|c|}
\hline Location & Year & Fatalities & RtoP & UNSCR \\
\hline Myanmar & 2006-2007 & 416 & $Y$ & $\mathrm{~N}$ \\
\hline India & 2006-2011 & 1855 & $N$ & $\mathrm{~N}$ \\
\hline Nepal & 2006 & 109 & $\mathrm{~N}$ & $\mathrm{~N}$ \\
\hline CAR & 2006 & 102 & $\mathrm{~N}$ & $\mathrm{~N}$ \\
\hline Afghanistan & 2006-2011 & 788 & $\mathrm{Y}$ & $\mathrm{Y}$ \\
\hline DRC & 2006-2011 & 5144 & $Y$ & $Y$ \\
\hline Somalia & 2006-2011 & 973 & $\mathrm{Y}$ & $Y$ \\
\hline Iraq & 2006-2011 & 4765 & $\mathrm{Y}$ & $\mathrm{Y}$ \\
\hline Sudan & 2006-2011 & 699 & $\mathrm{Y}$ & $Y$ \\
\hline Ethiopia & 2007-2008 & 268 & $\mathrm{Y}$ & $N$ \\
\hline Thailand & 2007-2011 & 754 & $N$ & $\mathrm{~N}$ \\
\hline Kenya & 2007-2008 & 434 & $Y$ & $\mathrm{~N}$ \\
\hline Chad, CAR, Sudan & 2007 & 267 & $\mathrm{Y}$ & $\mathrm{Y}$ \\
\hline Sri Lanka & 2008-2009 & 866 & $Y$ & $\mathrm{~N}$ \\
\hline Pakistan & 2008-2010 & 1252 & $\mathrm{~N}$ & $\mathrm{~N}$ \\
\hline Nigeria & 2008 & 123 & $\mathrm{Y}$ & $\mathrm{N}$ \\
\hline DRC, Uganda, Sudan, CAR & 2008-2011 & 2587 & $\mathrm{Y}$ & $\mathrm{Y}$ \\
\hline Guinea & 2009-2010 & 160 & $\mathrm{Y}$ & $\mathrm{N}$ \\
\hline Rwanda, DRC & 2009 & 202 & $\mathrm{~N}$ & Y \\
\hline Kyrgyzstan & 2010 & 470 & $\mathrm{Y}$ & $\mathrm{N}$ \\
\hline Cote d'Ivoire & 2010-2011 & 750 & $Y$ & Y \\
\hline Syria & 2011 & 1807 & $\mathrm{Y}$ & $\mathrm{N}$ \\
\hline Egypt & 2011 & 423 & $\mathrm{Y}$ & $\mathrm{N}$ \\
\hline Libya & 2011 & 1215 & $\mathrm{Y}$ & $\mathrm{Y}$ \\
\hline Yemen & 2011 & 350 & $\mathrm{Y}$ & $Y$ \\
\hline
\end{tabular}

TABLE 1: Security Council Resolutions by Country (Adapted from Table I. Bellamy 2013, 338-339)

In the above table the fatalities are best estimate and the final two columns indicate whether or not RtoP was invoked by a government, NGO, or the UN and whether there was a UN Security Council Resolution on that particular conflict as a result. Bellamy's full data set implies a number of conclusions. The first is that efforts to invoke RtoP in situations where other vital interests are of a primary concern have generally proven to be unsuccessful. In the cases of Myanmar, 
Ethiopia, Nigeria, and Guinea there are calls for RtoP to be invoked despite the relatively low number of casualties. Security Council did not follow from these arguably less obvious or egregious RtoP claims. This suggests that RtoP in and of itself is not a sufficient justification for intervention which may help to assuage the aforementioned Trojan horse concerns. The second implication is that the severity of the atrocity in and of itself is not usually sufficient enough to modify state behavior or lead to a Security Council resolution. The cases of India, Pakistan, Syria, and Sri Lanka show relatively high or moderate numbers of causalities with little or no action by the Security Council or associated groups for RtoP. Bellamy himself concludes, "This suggests that there is no clear linkage between the gravity of the problem in terms of civilian lives lost, the invocation of RtoP and the likelihood of Security Council resolutions" $(2013,341)$. These conclusions show that the Responsibility to Protect is a political issue, not a humanitarian or cosmopolitan one. The data presented here by Bellamy shows that alliances and relative power hold more sway in the state decision making process on whether or not to intervene or invoke RtoP than does the number of lives lost, thereby necessitating the effort to shift state priorities and highlighting the central issue. It also shows, as Bellamy states, that the invocation of RtoP can potentially elevate a situation that is less dire to one that requires or elicits decisive action - i.e. it becomes politically viable As Eckert correctly claims, "As long as the implementation of the responsibility to protect falls to states, states will be guided by their interests" $(2012,98)$. However, they also note that state interests are not static and can change 
over time. This highlights the need expressed also by Luck (2010) that political will is the most important aspect of implementing RtoP, i.e. making it in the interests of powerful nations to intervene. The ICISS report seems more determined to force states to comply with RtoP by redefining their responsibilities both domestically and internationally as opposed to making it in their interests to not only respect human rights at home but to foster the expansion of responsible sovereignty abroad. Chris Brown (Farer, et al, 2005) reminds us, "there is no clear-cut divide between humanitarian and non-humanitarian actions, and therefore any attempt to set up a system of rules for the former is likely to lead to a degree of frustration" (228). For Brown this is illustrated by the inability to conclusively decipher the actual state interests involved in intervention, i.e. whether a given intervention was carried out for humanitarian reasons or for other reasons under the guise of humanitarianism. Whether or not the prevention of atrocities is currently a vital interest of states in a position to carry out such prevention, Brown seems certain that it should be - "The desire to live in a world in which gross violations of human dignity do not take place, and a willingness to help to bring this about, is a legitimate state interest, as is promotion of the well-being of the nation, and the protection of the lives of its citizens, including the lives of its soldiers" (Farer et al 2005, 228). Legally, this desire is already reflected in the existence of jus cogens norms.

Brown's discussion of intervention as a state interest helps highlight a central problem with the $\mathrm{R} 2 \mathrm{P}$ concept, which is that the action itself is purported to be entirely altruistic by some proponents even though it requires that we impose a 
Western value system upon the nation within which we are intervening. Brown's explanation helps to alleviate the first problem by defining the humanitarian interest itself as a state interest instead of in the interest of humanity or the world society, or some such other vague cosmopolitan-inspired concept of natural law. By putting humanitarian intervention into comparatively more realist terms, the actions make more sense from a state-centric perspective. Furthermore, the intervention becomes less about imposing our values, and more about pursuing our interests as a nation-state. The distinction may seem semantic if the outcome is the same, however it seems more accurate and perhaps more "honest" to explain the intervention in terms of state interests rather than more "cosmopolitan" interests associated with altruistically helping citizens of other nation states. This conception also avoids somewhat the problem of imposing an international, cosmopolitan concept of Western ideals, because they are now just the interests of a particular state, not purported to be universal in any way. By placing humanitarian interventions in a state-centric context, we effectively "own" the intervention as a state interest as opposed to a claim that we serve some kind of higher interest belonging to international society.

Alex J. Bellamy believes that RtoP has the power to shape important contextual and historical factors like legitimacy. Although this is potentially true of any norm in the international context, the goal for Bellamy seems to be changing the values, ideas, and interests of states in a decidedly constructivist approach through "naturalization and internalization" of the norm or idea $(2013,344)$. Finnemore 
believes that these value changes are already occurring; "Strong states continue to intervene in weaker states on a massive scale when it suits them. What has changed is when it will suit them - not the fact of intervention but its form and meaning. What have changed are the state understandings about the purposes to which they can and should use force" $(2003,3)$. Finnemore suggests that legitimate humanitarian concerns are being folded into the vital interests of states through continued use and normative acceptance over time.

International organizations also have an important role to play in shaping state interests. International organizations can alter or affect state priorities and/or policies which in turn create new departments and institutional positions domestically which then affects internal policies (Alvarez 2009). The ICISS asserts, "good international citizenship is a matter of national self-interest" $(2001,36)$. If this is true, then if RtoP is accepted as a norm throughout international organizations, governmental or other, it would behoove nations as good international citizens to accept it, thereby altering their own behavior and policies in accordance with it. 
Chapter 3: Case Studies - Kosovo, Libya, Syria

\section{Introduction}

In light of the exploration of the issues most central to the Responsibility to Protect it is now possible to explore some of the practical applications of it within the last few years in order to determine where the norm currently stands. This goal is pursued in this third chapter by conducting a critical examination of two of the most recent and most high profile cases wherein RtoP was invoked by a government, NGO, or international organization - The Libyan intervention and the Syrian Civil War spurred by the Arab Spring in 2011. A comparison of these two cases helps highlight the relative effectiveness of RtoP and its normative status within the international community. The case study begins, however, with an overview of the NATO intervention in Kosovo and how this sparked the evolution of the humanitarian intervention norm which eventually became the Responsibility to Protect.

Before beginning this exploration it is important to keep in mind the concept of linear development whilst considering the development of RtoP as a norm. As Justin Morris reminds us, it is essential that scholars and policy makers remain mindful that the development of norms in international law, especially one as disputed as RtoP, is not linear $(2013,1278)$. What Morris means by this is that even though norms may appear to move towards acceptance in light of positive cases of their application or rhetoric we must remain cautiously optimistic and not assume that the norm cannot also move "backwards," as it were, and be less accepted in 
light of failure or other developments in the international legal community. Morris writes, "The constant danger of reading too much into current events and the temptation to exaggerate the inductive potential of individual (and particularly infrequent) cases must be guarded against" (1280). This is not to say that individual cases should be discarded, but merely that the success of one case does not imply or prove incontrovertibly the widespread acceptance or application of the norm, and international legal scholars and policy makers should be aware of this fact. The following comparison of actual or potential humanitarian intervention and RtoP across three separate cases serves to illustrate this concept.

\section{Kosovo}

The case of the NATO intervention in Kosovo, along with the dubious action or inaction of the United Nations in the Rwandan genocide, is often cited as one of the international experiences essential to the formulation of a need for effective humanitarian intervention (ICISS 2001, U. N. General Assembly 2005, De Waal 2007, Thakur 2009). As this section shows, the international community learned many lessons from the unilateral NATO action in the Kosovo War, lessons which were subsequently applied to the formulation of the Responsibility to Protect. The following presents some of the details leading up to the intervention, the intervention itself, and some of the post-intervention issues and analysis. Throughout is reference to and analysis of Security Council resolutions 1160, 1199, and 1244 as they pertain to the evolution of humanitarian protection language and norms. 
The intricacies of the crisis in Kosovo eventually escalating into full-scale civil war, international intervention, and ethnic cleansing are varied and complex. There seems to be no simple explanation of the myriad causes of the conflict as they involve multiple actors and stretch back years before the actual war. This recounting does not attempt to provide a fully comprehensive understanding of all aspects of the conflict, but rather provides a brief explanation of the most important aspects as necessitated by our discussion of the Responsibility to Protect and the Kosovo crisis' hand in shaping it. The Kosovo Report put together by the Independent International Commission on Kosovo (IICK) (2000) provides a fairly comprehensive overview of the events leading up to the conflict and the details of the conflict itself. During the time of the conflict Kosovo was a part of the Federal Republic of Yugoslavia (FRY) and since having their autonomy revoked in 1989 they had been led locally by the League for a Democratic Kosovo (LDK). The subsequent conflicts within and regarding Kosovo can be attributed in large part to its ethnic composition. According to the IICK report, "Over the period 1961-81, the proportion of Albanians in the population of Kosovo rose from $67 \%$ to $78 \%$. This was due both to the very high birth rate of Albanians and to outmigration of Serbs and Montenegrins" $(2000,38)$. By 1991 the Serb population was only $9.9 \%$. As the Kosovar Albanian population continued to grow and gain political support through the LDK there was talk of independence and autonomy (IICK 2000, 48). The Serb minority in Kosovo was concerned that they were being oppressed and forced out 
by the Kosovar Albanians and clashes were occurring with increasing frequency and violence on both sides.

The concerns of the Serb minority in Kosovo bring us to the rise of Slobodan Milosevic, a controversial figure central to the analysis of this conflict. Milosevic ascended to the presidency of the FRY in 1997. According to the Commission, "The origins of the crisis have to be understood in terms of a new wave of nationalism that led to the rise of Milosevic and the official adoption of an extreme Serbian nationalist agenda" $(2000,1)$. Milosevic was able to rise to power partially through his support of the Serb minority in Kosovo - the Commission's report cites his infamous words of "No one should dare beat you," to Serbs clashing with police during a visit to Kosovo in 1987, after which he became a "national hero overnight" (40). The ethnic composition therefore became a central issue for Milosevic and his eventual presidency, which led to his Serbian nationalist agenda and repression against the Kosovar Albanians. The continued clashes and increasing violence gave rise to the Kosovo Liberation Army (KLA) in 1996, a violent group that aimed to achieve for Kosovo what they believed the LDK had not. The rise of the KLA prompted more violent and rigorous response from the Serbian government. As the Commission writes, "With the rise of the KLA, the already pervasive police harassment increased. The Serbian government proclaimed the KLA a terrorist organization, thereby justifying searches, detentions, and political trials" $(2000,53)$. FRY oppression and police presence in Kosovo continued to escalate, as did the KLA response. The Commission believes the hostilities finally came to a head and 
exploded into full-on war when, in February of 1998, Serbs arrested Adem Jashari, a prominent member of the KLA, and in the week after his arrest his extended family of 58 people was killed. After such a brutal show of force militias began to form in villages all over Kosovo $(2000,55)$.

After this point was passed and hostilities continued to escalate the international community could no longer tolerate inaction. In March, 1998 the United Nations Security Council passed Resolution 1160, in which the Council calls for an arms embargo on the FRY (including Kosovo), the cessation of hostilities and terrorist acts, and the political and diplomatic resolution of issues based on the condemnation of the "use of excessive force by Serbian police forces against civilians," and "all acts of terrorism" by the KLA (U. N. Security Council 1998). The resolution also warns of further action and additional measures by the Council in the case that there is a, "failure to make constructive progress towards the peaceful resolution of the situation in Kosovo" $(1998,4)$. One may note upon reading the resolution that there is no direct mention of humanitarian abuses or concerns as reasoning for the embargo, though the "territorial integrity" of the FRY is mentioned (and is also mentioned in subsequent resolutions). In the following months conflicts and skirmishes escalated as the Yugoslav government attempted to contain the fighting and avoid further provocation and increased involvement of international actors, however their attempts were unsuccessful.

Six months after Resolution 1160, with no apparent end to the fighting in sight, the Security Council passed Resolution 1199. Resolution 1199 contains bolder 
language and directly references the growing humanitarian crisis in Kosovo. The resolution states the Council is, "Gravely concerned at the recent intense fighting in Kosovo and in particular the excessive and indiscriminate use of force by Serbian security forces and the Yugoslav Army which have resulted in numerous civilian casualties and, according to the estimate of the Secretary-General, the displacement of over 230,000 persons from their homes" (U. N. Security Council 1998a, 1). The Council added "indiscriminate" to their list of adjectives to underscore the humanitarian element of civilian casualties, the concerns of impending ethnic cleansing, and the general refugee issue caused by the conflict. The Council also expressed concern about the "rapid deterioration in the humanitarian situation throughout Kosovo, [...] the impending humanitarian catastrophe," and "reports of increasing violations of human rights and of international humanitarian law" (1998a, 2). Most importantly the resolution also contains direct demands regarding the humanitarian concerns among their demand for a ceasefire and diplomatic resolution as opposed to just expressing concerns. The resolution states, "[The Security Council] Demands also that the authorities of the Federal Republic of Yugoslavia and the Kosovo Albanian leadership take immediate steps to improve the humanitarian situation and to avert the impending humanitarian catastrophe" (1998a, 2). The humanitarian language in Resolution 1199 is very strong, thus helping to set Kosovo as a precedent for humanitarian intervention.

The impotency of Resolutions 1160 and 1199 caused the NATO Alliance to consider military intervention as early as June 1998 (IICK 2000, 72). In a 
circumstance that will remain familiar throughout subsequent analysis of intervention on RtoP principles NATO got involved because of the fear of a Russian veto on any resolution authorizing military intervention. The ICISS quotes the London Times,

Diplomatic sources said yesterday that alliance members were approaching consensus on the legal basis for airstrikes. Although several countries, including Greece, Spain, Germany and Italy, had previously favoured seeking authorization from the United Nations Security Council, they now realized that was no longer realistic because of Moscow's pledge to veto military action. (2001a, 110)

Perhaps most frustrating was the fact that Russian officials seemed to be taking measures to avert continued conflict in Kosovo unilaterally on a diplomatic level but still frustrated the efforts of the Security Council with veto threats. The IICK notes, that there were some mixed signals and a "lack of policy coherence" according to the report as Russia simultaneously engaged in talks with Milosevic and Serbian officials while opposing action in the Security Council $(2000,144)$. The Chinese delegation also felt similar reluctance to legitimize and legalize action in Kosovo through the Security Council. The IICK report states, "China was also concerned that the UNSC was subject to manipulation by the United States and its allies, and thus should not be given any role in extending the Charter limits on the use of force" $(2000,145)$. Russia and China feared (and still fear) the status quo created by Western nations in positions of power within the United Nations. This anti-Western Russia/China dyad, examined in the previous chapter, is also present in the subsequent cases presented here, especially Syria. 
The NATO bombing campaign against Yugoslavia began on March 24, 1999, at $8 \mathrm{pm}$ local time. According to the official response the purpose of the operation was “to demonstrate the seriousness of NATO’s response to aggression, to deter Milosevic's escalating attacks in Kosovo, and seriously to damage Yugoslavia's military capacity to wage war in the future. The European leaders said about the same but stressed more strongly that the NATO intervention was necessary to prevent a humanitarian catastrophe" (IICK 2000, 85). Indeed it seems that humanitarian concerns were only weakly invoked by a few nations to justify the interaction. The ICISS Supplementary Volume notes, "In an emergency session of the Security Council on March 24, Russia, China, Belarus, and India opposed the action as a violation of the Charter. Of those states that supported the action, few asserted a clear legal basis for it. The US, Canada, and France stressed that the FRY was in violation of legal obligations imposed by Resolutions 1199 and 1203 . Only the Netherlands and the UK argued that the action was a legal response to a 'humanitarian catastrophe'" and was 'the minimum judged necessary for that purpose"' $(2001 \mathrm{a}, 112)$. This reading shows the limited role of humanitarian concerns leading up to the NATO bombings of the FRY in 1999 despite the strong wording of the preceding resolutions.

NATO proceeded with their operation without UN permission because they feared deadlock in the Security Council. This fear was subsequently confirmed when Russia and China proposed a resolution to declare the action unlawful and halt it (Henkin 1999, 825). This highlights a number of issues with humanitarian 
intervention and RtoP, mainly the legitimacy issue of unilateral action, and the seeming necessity to have the ability to circumvent the Security Council. It also shows the East/West grouping among the permanent members of the Security Council that still persists today and shows up in the subsequent case studies on Libya and Syria. Henkin writes, "as Kosovo illustrated, the Council, as presently constituted and under prevailing procedures, remains seriously defective and may sometimes be unavailable for that awesome responsibility," i.e. safeguarding against the abuse of humanitarian intervention $(1999,827)$. The composition and inner working of the Security Council have not changed significantly since the 1999 Kosovo intervention and subsequent resolutions passed, in spite of the efforts and ideas offered by scholars and diplomats in the previous chapter. The need to be able to circumvent the Council is also reflected in the RtoP writings, representing the precedential nature of the campaign.

The involvement of the international community and commencement of NATO bombings coincided with increased ethnic cleansing, displacement, and other humanitarian abuses by the FRY. According to the report the FRY began their ethnic cleansing, which they insisted was purely a military operation, in response to international involvement, but was not clearly "provoked" by said involvement. The FRY "blamed all human rights violations, especially the forced displacement of Kosovar Albanians, on NATO and the KLA" (IICK 2000, 88). With regards to these humanitarian abuses, the IICK reports, "In the period March 24, 1999 to June 19, 1999, the Commission estimates the number of killings in the neighborhood of 
10,000 , with the vast majority of the victims being Kosovar Albanians killed by fry forces" $(2000,2)$ and hundreds of thousands more were displaced. There were also many concerns about the effectiveness of the NATO operation itself. President Clinton expressly stated that the US government, as a part of the NATO Alliance, "had no intention of deploying ground troops to fight a war" (IICK 2000, 85). Coady refers to this as "cost-free intervention," believing that the refusal to put troops in harm's way "leads to the reliance upon remote forms of air power and technological wizardry that tend to shift the damage onto the largely blameless civilian populations, as happened to some degree in the bombing of Serbia" $(2008,95)$. The cost in casualties is thereby displaced onto civilian populations from the intervening army, in this case NATO forces. This allows the criticism that NATO was undercommitted to the operation in Kosovo and unwilling to risk casualties to prevent humanitarian catastrophe.

After an extended bombing campaign by the NATO Alliance the United Nations Security Council passed Resolution 1244 on June 10, 1999 which essentially legitimized the unilateral operation post hoc. Resolution 1244 directly references the "humanitarian tragedy," and the Council writes that they are, "Determined to resolve the grave humanitarian situation in Kosovo, Federal Republic of Yugoslavia, and to provide for the safe and free return of all refugees and displaced persons to their homes" (U. N. Security Council 1999, 1). In order to achieve these ends the Council set up UN peacekeeping forces to maintain and monitor relations between the FRY and Kosovo, demilitarize the KLA, monitor borders, allow for humanitarian 
aid to be administered, and address the refugee issue after a "verifiable phased withdrawal from Kosovo" by FRY forces. By passing Resolution 1244 the Council essentially legitimized the NATO intervention and officially intervened in Kosovo. As part of their rebuilding effort the Council set up what they call an "interim administration" to establish Kosovo's essential self-government and autonomy, begin reconstruction, establish the rule of law, protect and promote human rights, and "[organize] and [oversee] the development of provisional institutions for democratic and autonomous self-government pending a political settlement, including the holding of elections" (U. N. Security Council 1999, 4). The list provided in the Resolution does strongly resemble the Rebuilding sections of the subsequent ICISS document on the Responsibility to Protect. The Kosovo operation may have served as a template for the rebuilding portion of RtoP.

It is important here to touch once again on the norm of sovereignty. Throughout the Security Council resolutions on Kosovo the Council continue to reaffirm the sovereignty of the Federal Republic of Yugoslavia somewhere within the text. It is of interest to note that sovereignty is continually reaffirmed regardless of the content of the resolution itself, i.e. it seems more like lip service to the norm of sovereignty than any actual application or adherence to it. The bulk of Resolution 1199 in particular describes very specific and intrusive policy initiatives and goals for the Serbian government, including ceasing repression of resistance, allowing observers and aid, and establishing a timetable for resolution. Kohen and Del Mar note, 
The guarantees of respect of the territorial integrity of Serbia were expressly mentioned by members of the UNSC, both immediately preceding and following the adoption of UNSCR 1244. Indeed, a guarantee of the respect for the territorial integrity of Serbia was a conditio sine qua non for China to allow UNSCR 1244 to be adopted by abstaining during the voting process. $(2011,124)$

In spite of these promises and what I refer to as lip service to the norm of sovereignty, the United Nations essentially condones and assists in secession within the territory of another country. This shows also how Kosovo may serve as a negative precedent as well as a positive one, at least with respect to the sovereignty norm. It also shows where the ICISS derived their argument of an evolved norm of sovereignty. One gets the sense from the IICK report and the relevant Security Council resolutions that the relevant actors involved view Kosovo less as a case of violation of sovereignty and more how a legitimate humanitarian intervention was carried out. In short, the situation required intervention, and the traditional concept of sovereignty, though given lip service, is essentially forfeited. As shown in previous chapters this issue persists throughout the evolution of RtoP.

The Independent International Commission on Kosovo concludes their chapter on International Law and Humanitarian Intervention by outlining a number of "threshold principles" for humanitarian intervention taken from the lessons of the NATO intervention in Kosovo. They state that there are two valid triggers, "severe violations of international human rights or humanitarian law on a sustained basis," and "the subjection of a civilian society to great suffering and risk due to the "failure" of their state, which entails the breakdown of governance at the level of the territorial sovereign state" (IICK 2000, 193). They also stipulate that the primary 
goal of any humanitarian intervention should be, "direct protection of the victimized population," and that the operation must have reasonable chances of success, i.e. the operation must contribute directly to ending the catastrophe and be able to do so without incurring further unnecessary harm to civilian populations (IICK 2000, 194). The Commission goes on to state a number of contextual principles that include serious attempts at solutions falling short of military intervention, possible exercise of the Uniting for Peace mechanisms within the United Nations, strict adherence to the laws of war, and so on. In short, the Commission outlines most of the principles that end up comprising the content of the Responsibility to Protect.

The Commission correctly points out that the case of Kosovo is less a positive, precedent-setting example of successful humanitarian intervention, and more a case that exposes the problems inherent in international system with regards to humanitarian intervention at the time of its writing in 2000. The NATO intervention,

exposed the limitations of the current international law on the balance between the rights of citizens and the rights of states; it demonstrated the difficulties that ensue when even the most sophisticated and professional military forces are deployed to achieve humanitarian goals; it showed, in the un administration's difficulties in Kosovo, the immense obstacles that lie in the path of creating multi-ethnic cooperation in societies torn apart by ethnic war. (IICK 2000, 297)

The evolution of RtoP is an attempt to respond to and address these problems. The following passage from the conclusion of the 2000 Kosovo Report seems to be the seed of Responsibility to Protect thought and logic taken from the lessons learned in Kosovo; 
While the sovereignty of states is an essential element of human rights protection itself, sovereignty is frequently abused as a cover and justification both for abuse and for non-compliance with international norms. What is urgently needed is a code of citizenship for nations, which both protects states against unwarranted interference from outside powers, and guarantees their inhabitants remedies when their human rights are systematically abused. This ultimately implies changing the 'default setting' of the UN Charter, revising the so-called inviolability of sovereign states so that sovereignty becomes conditional on observance of certain minimal but universal and clear standards of behavior. (IICK, 291)

All of the aspects of RtoP are contained in this statement by the Independent International Commission on Kosovo. They directly address prevailing sovereignty norms and a wish to respect yet overcome them for humanitarian purposes, and the "certain minimal but universal and clear standards of behavior," and "code of citizenship for nations" are direct precursors to the Responsibility to Protect.

Falk writes, "In sum, unfortunately, the NATO initiative on behalf of Kosovo offers us a badly flawed precedent for evaluating future claims to undertake humanitarian intervention without proper UN authorization" $(1999,856)$. Kosovo shows us the importance of relying on the UN for legitimacy and legality, both cornerstones of the majority of scholarly opinion on RtoP. Most importantly, if nothing else, the issues raised in Kosovo spark important discussion and debate about bridging the gap between legitimacy and legality when it comes to humanitarian intervention. Brunée and Toope write, "Kosovo raised again the fundamental questions whether or not a norm of humanitarian intervention existed and, if so, who could invoke it, only the Security Council or individual states?" (2010, 62). Bellamy (2008) also argues that Kosovo is an important case study for 
highlighting the discussion on just cause criteria and thresholds, i.e. when is intervention necessary, legal, and legitimate. Kosovo forced world leaders and international organizations to confront the issue of humanitarian intervention and necessitated a discussion about intervention but it is thereby not precisely an example of its failure, especially since it was carried out unilaterally outside of the United Nations. If anything it is an example of why the discussion needs or needed to occur.

International legal scholar Louis Henkin believes that there is not a clear or conclusive hierarchy of norms or legal principles at the time of the Kosovo War. Henkin writes,

The principles of law, and the interpretations of the Charter, that prohibit unilateral humanitarian intervention do not reflect a conclusion that the "sovereignty" of the target state stands higher in the scale of values of contemporary international society than the human rights of its inhabitants to be protected from genocide and massive crimes against humanity. (1999, 824-5).

According to this formulation intervention and sovereignty are both international values and it is not clear that one necessarily stands above the other, though there is certainly more legal basis for the latter. What the subsequent country case studies show, however, is that humanitarian justifications are often unclear and not uniformly applicable, especially because they require specific action as permissive norms as opposed to sovereignty which is prohibitive in nature. The sovereignty norm is more fairly and accurately adhered to, whereas intervention relies on the whims of the actors carrying out the intervention. This difficulty revealed by the 
international experiences in Kosovo necessitates the development of collective means of intervention.

The final principles of humanitarian intervention put forth by the IICK in light of the events in Kosovo are clearly a precursor to the Responsibility to Protect and the subsequent principles presented by the ICISS in 2001. They consist of three threshold principles and eight more contextual principles. The valid triggers are "severe violations of international human rights or humanitarian law on a sustained basis," and "the subjection of a civilian society to great suffering and risk due to the 'failure' of their state, which entails the breakdown of governance at the level of the territorial sovereign state" (IICK 2000, 293). The second trigger is especially reminiscent of RtoP insofar as states being unable or unwilling to fulfill their sovereign duty to protect their population. The other two threshold principles essentially state that the primary purpose for intervention must be humanitarian (just cause principle), and that prevention or ceasing of humanitarian catastrophe must be feasible (reasonable chances of success principle). The contextual principles essentially foreshadow the prevention and rebuilding aspects of the intervention, with particular stress on the legitimate efforts to prevent abuses such as sanctions, diplomatic talks, and other peaceful solutions, as well as other Just War principles (IICK 2000, 293-4). The lessons learned from the Kosovo War as reflected by the Independent International Commission on Kosovo clearly foreshadow the eventual formulation of the Responsibility to Protect. 
Libya

Many scholars, international relations theorists, and UN officials regard the multilateral UN sanctioned action in Libya to be a clear victory for RtoP and a good example of its application to a specific situation. Edward Luck (2011) refers to the Libyan intervention as the first explicit invocation of RtoP in a Chapter VII context. Libya is also the first real practical application of RtoP since the lessons learned from Kosovo in 1999, thereby allowing us to analyze how the norm has evolved in the subsequent years and whether the lessons learned are properly applied. This section turns a critical eye upon the UN sanctioned NATO intervention in Libya to provide a comprehensive and in-depth understanding of how RtoP's application therein affects and reflects its normative development.

Protests against Muammar Qaddafi's allegedly oppressive and tyrannical rule in Libya began in February 2011. During the ensuing days of protest the Libyan security forces under the command of "Brother Leader" Muammar Qaddafi reportedly killed at least 109 protestors (Eckert 2012). Five days after the onset of protests on February 17, Qaddafi made a public statement against the protests in which he pledged to, "purge Libya inch by inch, room by room, household by household, alley by alley, and individual by individual until the country is purified" (Amnesty International 2011, 16). Such violent, inflammatory rhetoric by a leader towards their own population did not escape the notice of the international community. In a welcome change from the prolonged inaction of the international 
community in Kosovo that allowed the conflict to worsen, the United Nations Security Council was able to initiate discussion and action in Libya.

On the $26^{\text {th }}$ of February the Security Council passed Resolution 1970, in which they "recall" the Libyan authorities' responsibility to protect its population and demand an immediate end to the violence (U. N. Security Council 2011). The humanitarian language in Resolution 1970 is fairly strong and, indeed, more expansive in some ways than Resolution 1199 on Kosovo. The Council "condemns" and "[deplores] the gross and systematic violation of human rights" committed by the Libyan government upon civilians, expresses concern about the refugee issues created by the conflict, and welcomes further investigation into the alleged violations of international human rights law (U. N. Security Council 2011, 1). These phrases are not particularly unusual or unlike the Kosovo resolutions. However, the Council includes as a gross and systematic violation of human rights, "the repression of peaceful demonstrators," and "the incitement to hostility and violence" (U. N. Security Council 2011, 1). Perhaps in their fervor to properly apply their first case of RtoP the Council hastily set the threshold incredibly low. The repression of peaceful demonstrators, though unfortunate and regretful, is not an established violation of international human rights law. Under Chapter VII the Council calls for an end to the violence, restraint on the part of the Libyan government, an ICC referral, arms embargo, and other sanctions against Libyan officials. As with the Council's resolutions on Kosovo they pay lip service to the sovereignty, independence, territorial integrity and national unity of Libya. Another very important part of 
Resolution 1970 is the inclusion of condemnations by Libya's regional neighbors, the Arab League, the African Union, and Secretary General of the Organization of the Islamic Conference. The regional support for the Security Council resolutions on Libya was a vital part of its acceptance and a very indicator of multilateralism and, therefore, legitimacy.

Resolution 1970 did not lead to the immediate cessation of violence, therefore the Security Council passed Resolution 1973 on March 17, 2011, in which they reiterate the first pillar of the responsibility to $\operatorname{protect}^{8}$ and establish a No-Fly Zone and reinforces arms embargo and other sanctions from Resolution 1970 (U. N. Security Council 2011a). Perhaps realizing that the legitimacy of their RtoP thresholds were at stake the Council's language on humanitarian abuses is a bit stricter in Resolution 1973. They continue to condemn humanitarian abuses, however their examples are more in line with more well-established triggers, including torture, executions, and enforced disappearances. The Council's language regarding the alleged abuses is also less succinct, allowing for a fair amount of interpretive leeway. In their reasoning the Security Council states, "Considering that the widespread and systematic attacks currently taking place in the Libyan Arab Jamahiriya against the civilian population may amount to crimes against humanity [emphasis mine]" (U. N. Security Council 2011a, 1). Resolution 1973 takes a step back from the fairly strong, low-threshold humanitarian language and focuses on

8 "Reiterating the responsibility of the Libyan authorities to protect the Libyan population and reaffirming that parties to armed conflicts bear the primary responsibility to take all feasible steps to ensure the protection of civilians" (U. N. Security Council 2011a, 1). 
the role of the Security Council in addressing threats to international peace and security. The significance of Resolution 1973 should not be taken lightly, however. Since the Kosovo air campaign had been carried out by the NATO Alliance prior to the post hoc legitimization by the Security Council, Libya marks the first legitimate assertion of RtoP principles. As Morris notes, “In passing Resolution 1973 [...] the UN mandated, for the first time in its history, military intervention in a sovereign state against the express will of that state's government" $(2013,1271)$. Within two days of Resolution 1973 NATO forces began bombing Libya's air defenses, effectively leveling the playing field between government and opposition forces. This allowed the rebel forces to seize control of the Tripoli, the Libyan capital, in August and effectively end the rebellion. Qaddafi was killed by opposition forces in October 2011.

Alex Bellamy is one who cites the Libyan intervention as a positive example of RtoP enforcement. He writes, "the signs from Libya suggest that the establishment of modest early-warning, assessment, and convening capacities can have a positive effect on policy planning and decision-making" (Bellamy 2011a, 264). Bellamy's assessment of the Libyan intervention shows what RtoP is potentially capable of achieving in a positive way. Bin Halal and Schwarz (2013) note that the decisively multilateral character of the intervention made it very successful with respect to the development of the RtoP norm. Thomas Weiss believes that RtoP in Libya has the opportunity to strengthen the norm, and that since 2005 normative trends on the invocation of RtoP and humanitarian 
intervention seem to be growing in favor of those norms or policies (Weiss et. al. 2011). The research shows that a large number of scholars regard Libya as a success for RtoP. When compared to the legitimacy issues and unilateral nature of the Kosovo War it is hard to disagree. Libya represents a case wherein humanitarian catastrophe was foreseen and averted, or at the very least rapidly stopped, by direct, multilateral action through the United Nations. The operation was carried out swiftly and with purpose. Beyond and underneath these objective indicators, however, there lies a manifestation of many of the inherent issues of RtoP outlined in the previous chapters.

Much of the literature cited suggests that pro-RtoP scholars recognize that RtoP must be adopted by the great powers for the norm to become naturalized, embedded, and ultimately accepted - this is one of the reasons why many point to its execution in the Libyan case as a good example of its spreading acceptance. However, Justin Morris (2013) suggests that scholars and researchers have given RtoP more credit than perhaps it deserved in the decision making of the UNSC to intervene, particularly in Libya. Upon analyzing a vast majority of the pro-RtoP literature, one may draw the conclusion that Libya was a resounding success for the norm. The Morris article sheds a fair amount of light on this assertion. Germany, China, India, Brazil, and Russia all expressed concerns over the application of RtoP in Libya for various but related reasons, and the Resolutions on Libya $(1970,1973$, 2016, and 2040) refer only to the first pillar of RtoP (sovereign responsibility) without making any explicit judgments on the second and third pillars 
(international responsibility). According to Morris this suggests, "R2P remains controversial and contested, and subject to a far lesser level of norm-cascade than is often suggested in scholarly literature" $(2013,1273)$. Morris' analysis shows that the Libyan intervention, even if considered successful, was not an overwhelming victory for the Responsibility to Protect and further that the pro-RtoP community may be incorrectly evoking the relative success of the Libyan intervention to show a positive normative development.

What much of the pro-RtoP literature lacks is the recognition that the Libyan was especially unique and incredibly specific - it was a case in which the application of RtoP was relatively uncomplicated for a number of factors not easily duplicated across all cases. Hehir refers to the occurrence of the Libyan intervention as "aberrant, albeit welcome, behaviour impelled by a unique constellation of necessarily temporal factors" (Weiss et. al. 2011, 19). Among these factors are the relative straightforwardness of the abuses and intent to abuse, the lack of vital, conflicting state interests, the involvement of regional institutions, and Muammar Qaddafi's relative lack of allies either in the region or, most importantly, within the Security Council. First, the language that Qaddafi used in his pursuit the rebels was very obviously inflammatory, extreme, and dangerous. Aside from his promise to "purge" and "purify" Libya of dissent, Bellamy writes, "In words that bore direct echoes of the 1994 Rwandan genocide, Qadhafi told the world that 'officers have been deployed in all tribes and regions so that they can purify all decisions from these cockroaches' and 'any Libyan who takes arms against Libya will be executed'" 
$(2011,838)$. It is very clear that this kind of language is relatively unusual, thus inviting the comparison with the Rwandan genocide. Secondly, "the Arab League, including Libya's neighbors, endorsed the action-a testament to Qadhafi 's political isolation," and "the governments of Russia and China, often reluctant to support intervention, chose to abstain rather than veto crucial UN Security Council resolutions" (Albright and Williamson 2013, 16). In short, Qaddafi's years of aberrant and unusual behavior made sure that he had no real allies by the time the decision to intervene was made, thereby making the decision relatively very easy politically. Albright and Williamson also note that the operation was relatively easy militarily, due to “the modest capacity of Libya's armed forces, the open desert landscape, and the country's proximity to Europe and allied military bases aided the military aspects of the operation" $(2013,16)$. All of these factors help highlight how relatively easy the intervention in Libya was politically, militarily, and diplomatically. The decisive factors that led to intervention in Libya are not likely to be duplicated across all cases. It may therefore be premature to conclude the success of RtoP principles based on the Libyan operation if they can only be applied in the easiest and most obvious cases.

Mohammed Nuruzzaman believes that a critical review of the Libyan intervention reveals three different ways in which the intervention was injurious to RtoP; military force was resorted to with incredible swiftness, there was "double commission of war crimes and crimes against humanity," and the rebuilding policy was morally and ethically dubious $(2013,63)$. The timeframe between the call for 
RtoP and a Security Council Resolution authorizing the use of force was incredibly short - less than a month all told. Compared to the six month timeframe between Resolutions 1160 and 1199 and then the subsequent six months from Resolution 1199 to the NATO Alliance campaign in Kosovo the Libyan operation seems incredibly swift. There were little to no efforts to engage in preventative diplomacy, talks, etc., all prerequisites for the legitimacy of RtoP as stated by the ICISS in 2001 and many scholars since. With respect to the "double commission of war crimes," Nuruzzaman believes that the NATO forces stepped in too quickly and essentially helped the opposition movement commit their own war crimes as the number of casualties skyrocketed and the conflict was pushed into a full-blown war $(2013,64)$. Lastly, he claims “NATO left Libya after Gaddafi was killed, leaving behind [rebel forces] plagued with internal divisions and unable to address serious issues of national reconciliation and unity" $(2013,65)$. The rebuilding portion of RtoP seems to missing from the Libyan intervention according to this analysis. The swiftness of Security Council action in Libya is both refreshing in light of a comparison to the painfully long periods of inaction in Kosovo, and distressing in light of the positive normative development of RtoP through practical application.

Clearly there are those who question whether or not Libya was indeed a success for the Responsibility to Protect. On a purely observational level the operation was successful in that abuses were prevented/halted and RtoP was evoked, at least in part, as a major portion of the reasoning for the No-Fly zone and subsequent NATO military action, much like in Kosovo. Critics point out that the 
inclusion of RtoP in the Security Council resolutions on Libya was more controversial than other researchers suggests, and that the operation itself was not carried out in line with RtoP specifications or at the very least that the operation was far from ideal. At the very least, however, it would not be unfair to conclude that the experiences in Libya were exponentially better than the NATO experience in Kosovo more than ten years prior, thus suggesting a positive evolution of the RtoP norm. The Libyan intervention was undoubtedly a better example of humanitarian intervention than was the intervention in Kosovo, however this relative improvement of practical applications does not indicate that the operation was objectively successful upon a comprehensive analysis. As Morris warns, we must be cautious not to measure the success of the operation only in comparison to "worse" examples like Kosovo and thereby risk reaching false conclusions about RtoP's normative development.

\section{Syria}

If Libya was a success for the Responsibility to Protect the lack of its successful application in Syria is almost definitely a failure for its proponents. The disputable success of the Libyan intervention has led a number of observers to question whether or not RtoP really has been adopted as an international legal norm, with a number of scholars and international leaders lauding the operation as a successful example of the norm's adoption. One of the prerequisites for a concept to become a norm is its continued and comprehensive application, its compliancepull, and its ability to influence the behavior of states. Once again, we must be 
careful in our assessments and remember that the development of norms is not linear. This section examines the conflict in Syria and what inaction by the Security Council says about the current development and status of RtoP as an accepted norm.

The Arab Spring protests had already spread to Syria by March 2011 when a group of about 200 protestors gathered to demand the resignation of Syrian President Bashir al-Assad. According to numerous reports, this protest and the ones that followed were often met with allegedly unnecessary lethal force by Syrian security forces who are quite numerous and also very loyal to the al-Assad government (Eckert 2012). Table 1 (Political Will and State Interests) puts the fatalities in Syria at 1807 in 2011. However, since then the conflict has been upgraded to a full-on civil war, and the CIA reports the death toll at over 100,000 (CIA 2013), though this number includes Syrian government forces and opposition forces among the number of civilians killed. Luckily for Assad, he has more allies within the Security Council than did Qaddafi, and the luck to have his uprising occur in such close temporal proximity to the Libyan intervention. Both Russia and China have blocked any meaningful Security Council action on Syria. The situation in Syria continues to deteriorate and there has yet to be a Security Council resolution specifically regarding the protection of civilian populations or the responsibility to protect as of this writing 9 . The conflict in Syria has persisted for three years without substantial Security Council involvement.

\footnotetext{
${ }^{9}$ Security Council Resolution 2118 (United Nations 2013), passed 27 September, 2013, refers specifically to the non-proliferation and prohibition against the use of chemical weapons, an altogether separate norm. I do not believe it is prudent to
} 
The hypocrisy of this failure to intervene is staggeringly obvious. Shanahan writes, "those very conditions that were cited as the justification for a military response under R2P existed in Syria and yet the international community has only enacted sanctions and issued condemnations" (Weiss, et. al. 2011, 27). Security Council Resolution 2118, the only resolution issued against Syria at this time, not only does not mention RtoP (its focus is the chemical weapons ban), it specifically defends the sovereignty of the Syrian Republic and stresses the need for a Syrian-led diplomatic solution, i.e. the Syrian government is not determined to be in violation of their responsibility to protect. The Action Group for Syria, consisting of Secretaries-General of the United Nations and the League of Arab States, Ban Kimoon and Nabil Elaraby, respectively, the Foreign Ministers of the five permanent members of the Security Council - China, France, Russia, the United Kingdom and the United States of America - as well as the Turkish Foreign Minister, the High Representative of the European Union for Foreign Affairs and Security Policy and the Foreign Ministers of Iraq, as Chair of the Summit of the League of Arab States; Kuwait, as Chair of the Council of Foreign Ministers of the League of Arab States and Qatar, as Chair of the Follow-up Committee on Syria of the League of Arab States (UN News Centre 2012), writes that, "They strongly condemn the continued and escalating killing, destruction and human rights abuses. They are deeply concerned at the failure to protect civilians, the intensification of the violence, the potential for even deeper conflict in the country and the regional dimensions of the problem."

count this resolution as contributing to the advancement or application of the Responsibility to Protect. 
However, the very next paragraph states, "The members of the Action Group are committed to the sovereignty, independence, national unity and territorial integrity of the Syrian Arab Republic" (United Nations 2013, 9). Though the sovereignty lipservice is not usual, the language in this resolution adheres much more closely to the traditional concepts of sovereignty than to the redefinition of sovereignty presented by the Responsibility to Protect.

The Responsibility to Protect has not yet been explicitly invoked in the Syrian case even though a number of similar factors exist. The only specific reference to RtoP in Syria comes in the form of a concern expressed by Russia that it may be abused if applied in Syria;

Russia suggested that the "international community [was] alarmed" by the prospect that Libya might become "a model for future actions of NATO in implementing the responsibility to protect." This is the only explicit reference to R2P made in the Council so far by either Russia or China in relation to Syria. (Morris 2013, 1276)

This suggests extreme hesitance to apply RtoP in Syria for a number of reasons. The Russian representative either does not want RtoP to develop in a positive direction as a norm and is therefore hesitant to apply it in Syria, or they fear that its continued application will serve to reflect negatively upon it and thereby delegitimize it. It is also clear that the Russian representative regards the timing of the proposed Syrian intervention to be problematic; "Russia insisted to fellow Council members that 'the situation in Syria cannot be considered in the Council separately from the Libyan experience'" (Morris 2013, 1275). Perhaps it was the quick succession of considerations that worried China and Russia. Seen in light of the relatively quick 
actions in Libya this caution may be understandable. Morris also highlights that there were concerns expressed about regime change as the primary objective, such as eventually occurred in Libya.

As explored in the previous section the Libyan intervention was incredibly unique in character and relatively straightforward. The situation on the ground in Syria is infinitely more complex and more closely resembles the Kosovo case. Syria is very religiously and ideologically diverse. The CIA World Factbook (2013) reports the population is $74 \%$ Sunni Muslim (Islam - official), $16 \%$ other Muslim, which includes Alawite and Druze, 10\% Christian, and a "tiny" Jewish community spread throughout the major cities. To make matters worse, the Assad family is Alawite, and effectively has stayed in power for more than 40 years through their "coalition of minorities" - it also appears, according to some reports, that the vast majority of armed rebels are Sunni Muslims (Carpenter 2013). This gives the conflict in Syria a decidedly ideological angle, which is potentially much more difficult to reconcile than a political one and arguably more volatile. The demographic and ethnic composition of Syria and Assad's minority loyalties are also reminiscent of Milosevic's support of Serb minorities in Kosovo. Carpenter (2013) also concludes that Syria is not only difficult domestically, but serves as a locus for international geopolitical rivalries as well, both within the Middle East and the West.

Eckert (2012) compares the Syrian and Libyan cases and concludes that the prioritization of state interests is shown partially in the difference between RtoP application in Libya and Syria respectively. In Libya the cost of intervention was 
low, not only militarily but politically as well, and in Syria there exists a conflict of interest among the members of Security Council, thereby making decisive action problematic. The Syrian case illustrates quite well how state interests shape the decision to intervene, or even evoke RtoP at all, and how difficult it is to apply RtoP across all situations that may call for its use. Unlike in Libya there are a myriad of geopolitical and security interests that intersect in Syria, Assad has allies in the region and in the Security Council, and he has been less inflammatory and has even cooperated with international pressures in accordance with Security Council Resolution 2118 by giving up his stock chemical weapons. Albright and Williamson sum up the conclusions reached by an examination of the Syrian conflict quite well;

The terrible carnage in Syria illustrates that the international community's embrace of R2P is not sufficient, in itself, to prevent a ruthless dictator from inflicting grievous harm on his own citizens, especially when the permanent members of the Security Council are divided and external military intervention is difficult. $(2013,17)$

The Syrian case is one that illustrates, in real time, the realization of nearly all of the concerns and issues explored in the previous chapter. The fact that it also more closely resembles the experience in Kosovo than the much more recent Libyan intervention also shows the non-linearity of the normative development taking place.

There are a number of similarities between the Syrian case and the events leading up to the NATO intervention in Kosovo explored earlier in the chapter. We have a populace divided among ideological and ethnic lines, and a leader that is loyal to, or at the very least protective of, a minority population. There is also the tacit 
support of one or more permanent members of the Security Council and an ideological and geographical dyad between East and West. The relationship with Russia and their Chinese allies allows Assad to avert direct international intervention in a way that Milosevic was not. As the IICK writes, "The internationally isolated Yugoslav government misjudged the international reaction" $(2000,89)$. Assad and his allies are clearly more aware of the international situation and response - clearly those who wish to test the limits of international humanitarian law have learned their own lessons from Kosovo and Libya. We see in Syria the lessons of both Kosovo and Libya exerting pressure. If intervention in Kosovo, a similar situation, has been justified post hoc by the Security Council why then is this situation in Syria allowed to continue? This once again illustrates that RtoP is based more on political concerns than humanitarian ones and is incredibly difficult to apply equitably.

It is here that we echo Morris' warning that norms do not always (or perhaps ever) develop in a linear fashion in international law. Some view the Libyan intervention as a clear success of RtoP (though there are those who contest even that conclusion), however the lack of Security Council action in the face of similar atrocities ${ }^{10}$ serves to highlight the reality that the evolution of the Responsibility to Protect can indeed move backwards, and that we should be cautious in lauding its success before it has earned such commendations or acceptance.

${ }^{10}$ Nuruzzaman refers to the Security Council's "bizarre indifference to Bahrain and Yemen" in reference to RtoP's inconsistent application $(2013,66)$. 
Chapter 4: Conclusions and Lessons

\section{Introduction}

The preceding examination of the Responsibility to Protect and some relevant case studies leads to the conclusion that the principle is incredibly flawed in a number of ways and faces many years of continued tension and controversy on the path ahead. Flawed as its implementation may be the end goal of RtoP is a noble one and it could be argued that the concept should not be entirely abandoned based on its relatively short track record. This final chapter addresses some of the positive developments of RtoP and discusses their importance in moving the norm forward into the future. This chapter explores some of the potentially most effective mechanisms for the adoption of RtoP, including the regional and institutional focuses, as well as how the effectiveness of RtoP is or can be measured in practice. The discussion continues with a brief look at the position and policy of the United States, a nation whose normative influence in the international community cannot be understated. The chapter is capped by a relatively brief conclusion reached through consideration of all the factors presented in this study.

\section{The Regional Option}

The preceding survey of the literature reveals that the successful and effective application of RtoP may rely in large part upon the cooperation of regional organizations and nation-states. From the ICISS Document, “Chapter VIII acknowledges the existence and security role of regional and sub-regional 
organizations, but expressly states that 'no enforcement action shall be taken under regional arrangements or by regional agencies without the authorization of the Security Council"' (48), and "It has long been acknowledged that neighbouring states acting within the framework of regional or sub-regional organizations are often (but not always) better placed to act than the UN, and Article 52 of the Charter has been interpreted as giving them considerable flexibility in this respect" (53). There are a number of reasons why a focus on regional organizations helps to solve some of the conceptual issues inherent in RtoP.

The analyses conducted by Glanville, Bellamy and others of the relatively effective execution of an RtoP intervention in Libya suggests that the influence of regional organizations like the League of Arab States was instrumental to amassing the political will to act. Glanville writes, "in the absence of sovereign consent, this regional consent was crucial in convincing skeptical states to acquiesce and in generating the will among other states to push for the authorization of military intervention to protect civilians" $(2013,336)$. This regional context can blunt the image that a given intervention is strongly motivated solely by the interests of powerful states external to the conflict. Bellamy and Williams refer to these regional organizations as "gatekeepers" that frame the issues and define the "range of feasible international action" $(2011,841)$. They note that up until this point there was little chance of there being any military action in Libya due to a large amount of opposition from influential countries, including two P5 members, however the acceptance of the possibility of intervention by regional actors led the Security 
Council towards consensus (Bellamy and Williams 2011). Furthermore, Bellamy et. al. assert in the same article that this same "gatekeeper" role was played by regional organizations leading up the intervention in Côte d'Ivoire. The original ICISS document similarly speaks to the importance of regional cooperation and provides Kosovo as a precedent. They write, "As the case of Kosovo demonstrates, it is essential to strike a balance between the responsibilities of international and local actors. International actors have the resources to help provide a secure environment and to begin the reconstruction process" $(2001,45)$. The conclusions asserted by Bellamy, Williams, Glanville, and the ICISS suggest that regional organizations can help to frame the negotiations and discussions leading to intervention under the Responsibility to Protect by providing important contextual clarity.

There are those who believe that the role of regional institutions cannot be overstated. Bellamy's 2010 study boldly concludes that the League of Arab states was not only crucial to obtaining the political will in the Security Council to authorize intervention in Libya but that there never would have been a resolution without their approval. Bellamy writes,

The Obama administration had been cautious about the prospect of military action in Libya-because of concerns about military overstretch, potential casualties, budgetary implications, the potential for mission creep, absence of a clear exit strategy, and concerns about alienating states in the Middle East and elsewhere in the Muslim world-but the LAS resolution strengthened the hand of the interventionists within it. (843)

This course of events is not only interesting in and of itself, but seems to prove Bellamy's assertion that regional organizations and nations are incredibly 
influential as gatekeepers in a situation such as the one that occurred in Libya. Admittedly, the Libyan intervention was a very specific circumstance, however the situation remains telling. Bellamy's assertion suggests that a situation in which the US viewed its interests as being threatened would not have required the intervention or opinion of a regional organization, but in one like the situation in Libya where the US arguably could have gone either way, or indeed were leaning away from intervention, the smaller organization had relative power or sway in the push towards legitimizing the decision to intervene.

Another reason why this Regional Option is promising is that it helps to address the issues mentioned earlier that can be associated with attempting to assert universal moral values through cosmopolitan ideals. Regarding a report released in 2011 by Ban Ki-Moon, Glanville notes, "The Secretary-General recognized that the implementation of RtoP 'should respect institutional and cultural differences from region to region,' and he accepted that each region will operationalize the principle 'at its own pace and in its own way,'” and "different regions interpret different norms and values in different ways" $(2013,340)$. The observation by Glanville of the Secretary General's 2011 report shows that the United Nations as an international body believes that respect for the cultural and communitarian values of nation-states and regions is an important part of implementing any policy, especially one as potentially invasive as RtoP. This approach may help to implement RtoP in a way that is more sensitive to the needs and values of different communities. 


\section{The Institutional Approach}

Institutionalism, another mechanism for enforcing the development of RtoP as a norm, has a strong presence in the literature alongside the regional option outlined above. The thesis of this approach is that RtoP will be most effectively enforced and widely accepted by member states when the institutional mechanisms for its enforcement are well established in order to facilitate timely and efficient responses to crises as they occur and lower the costs associated with intervention. Thakur (Weiss, et. al. 2011) believes that without the development of an institutional framework for RtoP, responses to atrocities will continue to be ad hoc, unilateral, divisive, and case-by-case even if RtoP is eventually accepted as a norm this is evidenced by a comparison of the interventions in Kosovo, Iraq, and Libya. Thakur urges us to keep in mind, "Acceptance of the responsibility to protect norm no more guarantees 'humanitarian intervention' than its non-existence had foreclosed it as a tool of individual and collective statecraft" $(2009,18)$. This formulation acknowledges that RtoP does not create any additional obligations and therefore requires continued assertion, reformulation, and institutionalization. Ideally, RtoP attempts to address this by creating an institutional framework for prevention, action, and rebuilding, by involving regional organizations and neighboring countries, and strengthening systems of early warning.

The existing treaties and conventions regarding genocide, war crimes, etc. would not be emboldened or added to by a norm such as RtoP. What RtoP can do, however, is to establish effective frameworks and institutions for response and 
prevention, making existing legal obligations "more effective" as opposed to trying to create new ones (Strauss 2010,54). A constructivist view of this institutional development is that the norms materialize because of new concepts of interest and then the institutions eventually make those norms into laws once it is shown that they can be effectively adopted. It is hoped that, over time, "soft" codes of conduct may "harden" (Alvarez 2009). Observers like Alex Bellamy (2013) believe that these codes of conduct are already becoming habitual.

Alex Bellamy (2010) comes to the conclusion that the RtoP norm requires more advocacy and adoption as official policy, which will not only reduce the likelihood of future atrocities, but also make potential future atrocities easier to stop if they do begin because states will have built up institutional and diplomatic frameworks for dealing with the situations. This will make responding to atrocities easier, less expensive and less controversial, thereby making political will easier to attain. In Bellamy's view RtoP will ultimately be more effective if viewed as a policy agenda as opposed to some kind of "red flag" meant to generate political will on the fly. He claims, "RtoP is best employed as a diplomatic tool, or prism, to guide efforts to stem the tide of mass atrocities, and that it has little utility in terms of generating additional international political will in response to such episodes" (Bellamy 2010, 166). This is an accurate assessment in light of comparisons of past and present humanitarian interventions. The assessment highlights the need for and potential success of a robust institutional framework for RtoP. 
In their summation the ICISS ties institution building to financial concerns as well. The Commission believes that, at least with respect to prevention, institution building is more effective, more efficient, and most importantly much cheaper than the more ad hoc reactions to atrocities that have been carried out in the past, specifically citing the intervention in Kosovo (ICISS 2001, 71). Making prevention, reaction, and rebuilding cheaper provides financial incentive and makes the positive application of RtoP principles more likely, thereby enhancing its chances for success in normative development and acceptance. One way to enhance this goal is not only to create new institutions but to adapt existing ones to the purposes of enforcing RtoP. The International Criminal Court could potentially be used to streamline and institutionalize RtoP by being reformed and "empowered" to determine cases of RtoP violations, subject to certain constraints, which would then be referred to the Security Council for approval (Contarino and Lucent 2010). Adapting the ICC or ICJ for RtoP purposes would, however, require the most influential members of the United Nations Security Council to become signatories to the treaties that recognize them as legitimate.

\section{Peacebuilding Commission}

In order to address both the regional and institutional aspects of the Responsibility to Protect the Security Council formed the Peacebuilding Commission (PBC) in 2005 with Resolution 1645. In their reasoning for the establishment of the PBC the Council specifically refers to the "need for a dedicated institutional mechanism to address the special needs of countries emerging from conflict 
towards recovery," and "the important role of regional and subregional organizations in carrying out post-conflict peacebuilding activities in their regions, and stressing the need for sustained international support for their efforts and capacity-building to that end" (U. N. Security Council 2005, 1-2). The language and tone of the resolution leave a fair amount of room for societal and cultural values, gradual adoption and acceptance, and community participation. The organization is even structured to be more representative of the international community; "The Organizational Committee has a broad geographically representative membership, including seven members selected by the UN Security Council, seven members elected by ECOSOC, five based on financial contributions, five based on military contributions and seven elected by the UN General Assembly" (Lambourne and Herro 2008, 282). Since democratic deficit is one of the primary concerns of the legitimacy of the Security Council the form and purpose of the PBC may help to alleviate some of the issues presented here by using the Regional Option and the Institutional Approach.

The potential for the PBC to have a positive effect on the adoption of RtoP moving forward is moderate to high. In their study of why the PBC may work in addressing the difficulties inherent in humanitarian intervention, Lambourne and Herro write,

The PBC is mandated to consult with civil society and, although it has shown a reluctance to make significant progress in this domain in its first year of operations, it has the potential to institutionalise civil society interactions not only with the government concerned but also with regional organisations, UN agencies, the World Bank and IMF, and international and local NGOs. In this way the UN can act as a bridge between civil society and state and 
interstate actors with a view to empowering the former and holding the latter accountable. $(2008,289)$

The approach of the PBC contains precisely the kind of ground-up acceptance that RtoP will require to become a fully-fledged international legal norm. Furthermore, the structure of the Commission is such that members of the international community with regional ties can participate in decision making directly related to their regions, thus satisfying the issues related to regional context. The Security Council Report states, "Resolution 1645 stipulated that the PBC 'shall meet in various configurations' and that each configuration 'shall include as members, in addition to members of the Committee, representatives from the country under consideration'” (Security Council Report 2013, 4). Ideally these configurations will help to promote the regional participation and acceptance of RtoP, and provide more legitimacy to UN operations in this context.

The goal of the Peacebuilding Commission is one that helps address some of the issues presented and analyzed in the previous chapters; however it remains to be seen whether or not and to what degree it will be successful in achieving that goal. To ensure and monitor its effectiveness the PBC undergoes official annual review. According to the Security Council Report the PBC was initially determined by the official review committee to be relatively ineffective, lacking obvious progression towards their stated purpose. They outlined six issues that, if resolved, would help refocus the $\mathrm{PBC}$, among which were "the imperative of national ownership" and more field perspective (Security Council Report 2013, 3). As the Security Council Report states, “A field perspective was particularly important, 
according to the report, since it would bring a number of issues into relief, in particular: national ownership in the planning process and capacity-building; developmental aspects of peacebuilding; the need for coherence and coordination; and the importance of the regional dimension" $(2013,3)$. Addressing these issues effectively is vital to the working of the $\mathrm{PBC}$, especially insofar as it relates to resolving the most important issues examined here.

The Security Council Report states that the PBC's biggest impacts across all cases (Sierra Leone, Burundi, Guinea-Bissau, Central African Republic, Liberia, and Guinea) have come largely in the form of resource mobilization and advocacy. The relationship between the $\mathrm{PBC}$ and the Security Council seems to be vital to the PBC's effectiveness overall. As yet the PBC seems to have taken more of an advisory role to the Security Council, but the direct impact is less clear (Security Council Report $2013,7)$. If the Security Council avails themselves of the assistance of the PBC in applying RtoP principles it could turn out to be an important tool of institutional change and the evolution of the norm going forward. In this sense the PBC could serve the purpose of making RtoP more palatable and culturally sensitive over time - whether or not this initiative is ultimately carried out remains to be seen, though initial reports of the Commission's effectiveness are not incredibly promising in this regard. The Peacebuilding Commission certainly has the potential to facilitate the acceptance of RtoP and the most beneficial routes to its fair and legitimate application. Although its role seems to be largely advisory so far, this role may 
contribute greatly to affecting real, lasting organizational change within the UN given that they continue to progress towards their goals.

\section{Measuring Effectiveness}

How do we judge the success of a policy like the Responsibility to Protect? One of the ways to measure the success or failure of RtoP is to analyze the outcome of operations based on its invocation, such as has been done here in the cases of Libya and Syria. Though instructive, there are those believe that there are more accurate ways to measure the success of a norm in its developmental stages as its acceptance continues to oscillate. This sentiment is echoed by Badescu and Bergholm who believe," the appraisal of the responsibility to protect should not be reduced to the question of the effectiveness of a military response" (306). This section addresses some of the ways that we may effectively measure the "success" of the Responsibility to Protect within and outside of a military response.

As previously stated, the Responsibility to Protect is a political issue. We must, therefore, measure its success not only in terms of its actual outcomes, but also in how those outcomes appear or are represented. Edward Luck reminds us;

Whatever progress is being made in terms of structural and operational prevention, the headlines will focus on whether the invocation of the responsibility to protect and the application of related policy measures can, in all cases, stop those national leaders who are determined to be at war with their own people. $(2011,8)$

Conversely, Luck believes R2P should be judged not on stopping all of the abovemention cases, but on its ability to meet two outcome goals; 1) the successful prevention of large scale atrocities like Rwanda, and 2) timely and effective 
reactions in the unfortunate cases where prevention fails. Successful prevention is difficult to measure, as we have seen. Timely and effective reactions are easier, but that boils the success of RtoP down to military intervention once again.

Furthermore, measuring success requires that we carefully manage our expectations of what the Responsibility to Protect can and should achieve. There are those who believe that the expectations of RtoP interventions are inflated and that this may lead to continued disappointment (De Waal 2007). This may be due, in part, to the indeterminacy issue - it is not entirely clear in all cases exactly what it is that RtoP is trying to achieve and by what means. It may also be due to the political and practical difficulties of measuring the potential success of prevention.

One of the major barriers to assessing the effectiveness of RtoP is its inconsistent application over time across various cases. The examination of the Libyan and Syrian cases shows this difficulty. According to Shanahan, "The problem with the real-world invocation of R2P is that those political leaders quickest to justify military action based on the principle never explain why they don't call for it in apparently similar circumstances" (Weiss, et. al. 2011, 27). Perhaps this requires that the Security Council address not only their justifications for enacting RtoP as in Libya, but also provide explanations and justifications for inaction, as in the Syrian case. There may be a place for addressing the differences as opposed to just avoiding explanation.

In the end, measuring the effectiveness of RtoP requires reconciliation of most if not all of the issues explored in Chapter 2. It requires that we focus our 
attention on more than just Chapter VII enforcement through and by the Security Council. It requires that we be crystal clear about what is expected of RtoP and how it is carried out operationally and conceptually, i.e. a more determinate, specific framework. It requires that the international community accept the ICISS premise that the concept of sovereignty has changed to allow these interventions, and that the international community has been assuaged of their fears of the potential abuse of intervention. It also requires that we address and resolve the norm conflict between sovereignty and intervention. Measuring the success of RtoP will require an examination of how it resolves all of these issues, not merely how it carries out military operations.

\section{United States Position and Policy}

A number of prominent international relations scholars correctly believe that the role of the United States will be "pivotal" in the acceptance of the Responsibility to Protect as a norm both abroad in the United Nations and domestically in each member state (Albright and Williamson 2013, Weiss 2004). The United States is not only a member of the Security Council Permanent 5 but exerts significant cultural, economic, political, and diplomatic pressure upon the entire of the international community. As Weiss writes, "If military intervention to protect human beings is desirable, the critical task is to engage the United States in multilateral efforts" $(2004,146)$. This section examines the importance of the United States as an international actor and "norm legitimator," and analyzes the current US position and policy towards the Responsibility to Protect. 
The United States has the political, economic, and military power to create the institutions that will be crucial for the effective application of RtoP principles that lead to its acceptance. The United States is the only member-state to reach the ceiling rate of $22 \%$ for contributions, which is more than twice the percentage of the next highest contributing member-state as of February 2013 (Japan: 10.833\%) (U. N. General Assembly 2013). Similarly, as the world's most predominant military force the United States would have to bear a "disproportionate" financial and military burden of any international commitments in the name of RtoP (Groves 2008). Bellamy refers to the United States and the United Kingdom as "norm carriers" $(2005,39)$. That is to say that it would undoubtedly be nigh impossible to posit the acceptance of an international norm if the United States and its allies did not agree to such or abide by the norm's constraints, at least for the foreseeable future.

Analysis suggests that the United States will not to pre-commit themselves to a intervention or allow themselves to be obligated to intervene (Bellamy 2005). The US policy position is reflected also in their initial reservations to Security Council Resolution 1674 and the 2005 Outcome Document. Conservative pundits like Steven Groves agree with this approach, stating that RtoP "is inconsistent with a proper exercise of sovereignty, and any adoption of its principles is likely to constrain U.S. action in future situations" $(2011,1)$. This tendency makes it difficult to outline reliable and effective triggers for the Responsibility to Protect and any potential obligation to act. 
This relates closely to the political will issue. Albright and Williamson provide the following analysis;

Americans have a strong desire to help people in danger overseas; however, that sentiment is tempered by a fear of yielding control over decisions to multilateral organizations and becoming enmeshed in places where our engagement distracts from other priorities, is unsuccessful or underappreciated, or where costs exceed benefits. $(2013,20)$.

There is general agreement that American citizens, and especially American statesmen, regard their political autonomy in the international security arena to be a concern of the utmost importance. Anything that threatens that autonomy is not likely to be met favorably. This is reflected also in their unwillingness to sign some of the major treaties in international law. As Groves reminds us, "the United States has ratified neither the statute of the International Criminal Court nor the Additional Protocols on international humanitarian law" $(2,2008)$.

In regards to the Libyan intervention, Morris notes, "President Obama went to great lengths to publicly justify the action in terms of case-specific circumstances" (Morris 2013,1274). Libya also shows that the United States acts according to their own interests and not according to international legal interests in the same way. In his speech on the intervention in Libya, President Barack Obama is careful to state that the United States must always measure their interests against any calls for action, and states that there is an important strategic interest present as well (Obama 2011). Whatever the reason for these justifications, this suggests that the Obama administration did not want to present the intervention in the context of the Responsibility to Protect. The United States government is clearly cautious about 
evoking the Responsibility to Protect, though most likely for different reasons than Russia and China.

Engaging the United States in the Responsibility to Protect will be difficult but necessary as long as they hold the position of relative power they currently do. This would require the United States to agree to potentially constrain their own activities or be obligated to act abroad. It would also ideally require their ratification of the Rome Statute and the Additional Protocols. Along with the institutional and regional options outlined in this chapter, the acceptance of the United States is critical in advancing the goals of the Responsibility to Protect.

\section{Conclusion}

In the preceding work I have presented a comprehensive analysis of the Responsibility to Protect. I began by establishing a theoretical and conceptual framework of international law, upon which to build a healthy understanding of the issues that RtoP presents to that framework and vice-versa. The second chapter explored the practical limitations of those issues as they are expressed in accordance to the frames given in the first chapter. Without an understanding of the communitarian theoretical perspective and its conflict with the cosmopolitan perspective it would not be possible to understand the impacts of applying the Prevention portion of the Responsibility to Protect. An understanding of the legal implications of RtoP is deepened by the theories elucidates in the previous chapter. The third chapter provided three case studies that examined how RtoP began and how it has since been applied. The examination of the Kosovo case showed the roots 
of the Responsibility to Protect, and the cases of Libya and Syria exhibited how its evolution continues as is shown through relevant Security Council resolutions. This fourth and final chapter collected some of the lessons learned from the examination of the theoretical, legal, and practical issues of RtoP and presented them for consideration.

The International Commission, international legal scholars, and members of the United Nations are attempting to justify RtoP and facilitate its adoption by using a top-down approach, i.e. applying universal morality and logic through an international organization like the United Nations. As explored previously, making such assumptions about the legitimacy of a particular morality is problematic for a wide variety of reasons. Instead, proponents of the Responsibility to Protect should be focusing their attempts at the bottom-most layers of acceptance. The necessity for this bottom-up approach is shown by the exploration of the central issues conducted in Chapter Two. Many states and international legal scholars rightly resent the imposition of a particularly Western morality upon them and their policies. The good news is that this may not be necessary. The feasibility of the "bottom-up" approach is shown through the Regional and Institutional options outlined in this chapter. These two options respect the values and goals of nations who voices are often not well-heard in international organizations like the United Nations where there is a clear power dynamic expressed largely, but not solely, by the Security Council veto. The institutional approach attempts to strengthen the legitimacy of the institutions responsible for RtoP and the regional option extends 
respect and understanding to the smaller nations participating in the organization who are often the ones most strongly affected by its actions. These efforts in tandem frame the Responsibility to Protect more as a grassroots operation than forced or coercive imposition, a much more communitarian approach than is currently being attempted to the detriment of both RtoP and people upon which the concept is being forced.

It may come to pass that these approaches will not work, or that RtoP is doomed to fail to become a norm, or that it will remain forever in a state bordering on acceptance, or perhaps even that the global power centers will shift towards a different status quo and change the discussion altogether. Regardless, I believe this work presents a valid understanding of the concept followed by some potential steps that may further it. The critical examination of RtoP is not to question its validity and discard it, but rather to reveal its problems in order to more accurate address them. As the norm continues to evolve it remains to be seen which portions of RtoP remain and which are changed or discarded. The prevention of genocide, crimes against humanity, and purposeless human suffering deserves a critical eye and fair examination. The cost of forcing such an ideal before it is ready is not to be underestimated. 


\section{Works Cited}

Albright, Madeline K. and Richard S. Williamson. 2013. The United States and R2P: From Words to Action. United States Institute of Peace, United States Holocaust Memorial Museum, and The Brookings Institution. Accessed January 23, 2014.

http://www.brookings.edu/research/papers/2013/07/23-united-statesresponsibility-protect-albright-williamson.

Alvarez, Jose. 2009. "Legal Perspectives," in The Oxford Handbook on the United Nations, eds. Sam Daws and Thomas Weiss (Oxford University Press), accessed April 17, 2013, http://www.oxfordhandbooks.com/view/10.1093/oxfordhb/ 9780199560103.001.0001/oxfordhb-9780199560103-e-003.

Amnesty International. 2011. The Battle for Libya: Killings, Disappearances and Torture. London, UK: Amnesty International Ltd.

Archibugi, Daniele, and David Held. 1995. Cosmopolitan democracy: an agenda for a new world order. Oxford, UK: Polity Press.

Badescu, Christina and Linnea Bergholm. 2009. "The Responsibility To Protect and the Conflict in Darfur: The Big Let-Down." Security Dialogue 40, no 3: 287309.

Barnett, Michael and Martha Finnemore. 2009. "Political Approaches," in The Oxford Handbook on the United Nations, eds. Sam Daws and Thomas Weiss (Oxford University Press), accessed April 17, 2013, http://www.oxfordhandbooks.com/view/10.1093/oxfordhb/97801995601 03.001.0001/oxfordhb-9780199560103-e-003. 
Beitz, Charles R.. 1979. Political theory and international relations. Princeton, N.J.: Princeton University Press.

Bellamy, Alex J.. 2005. "Responsibility to Protect or Trojan Horse? The Crisis in Darfur and Humanitarian Intervention After Iraq." Ethics \& International Affairs 19, no. 2: 31-54.

Bellamy, Alex J.. 2008. "The Responsibility To Protect And The Problem Of Military Intervention." International Affairs 84, no. 4: 615-639.

Bellamy, Alex J.. 2010. “The Responsibility to Protect -- Five Years On.” Ethics and International Affairs 24, no. 2: 143-169.

Bellamy, Alex J.. 2011. "Libya and the Responsibility to Protect: The Exception and the Norm." Ethics and International Affairs 25, no. 3: 263-269.

Bellamy, Alex J. and Paul D. Williams. 2011. "The new politics of protection? Cote d'Ivoire, Libya and the responsibility to protect." International Affairs 87, no. 4: 825-850.

Bellamy, Alex J.. 2013. “The Responsibility to Protect: Added value or hot air?” Cooperation and Conflict 48, no. 3: 333-357.

Bellamy, Alex J. and Ruben Reike. 2010. "The Responsibility to Protect and International Law," in The Responsibility to Protect and International Law, eds. Alex J. Bellamy, Sara E. Davies and Luke Glanville (Leiden, The Netherlands: Martinus Nijhoff Publishers). 
bin Talal, El Hassan and Rolf Schwarz. 2013. "The Responsibility to Protect and the Arab World: An Emerging International Norm?" Contemporary Security Policy 34, no. 1: 1-15. Brown, Chris. 1992. International relations theory: new normative approaches. New York: Columbia University Press.

Brunnée, Jutta and Stephen J. Toope. 2010. “The Responsibility to Protect and the Use of Force: Building Legality?" in The Responsibility to Protect and International Law, eds. Alex J. Bellamy, Sara E. Davies and Luke Glanville (Leiden, The Netherlands: Martinus Nijhoff Publishers).

Brunstetter, D. and Megan Braun. 2013. "From Jus ad Bellum to Jus ad Vim: Recalibrating Our Understanding of the Moral Use of Force." Ethics \& International Affairs 27, no. 1: 87-106.

Carpenter, Ted. 2013. "Tangled Web: The Syrian Civil War and Its Implications.” Mediterranean Quarterly 24, no. 1: 1-11.

Chandler, David. 2004. "The Responsibility to Protect? Imposing the 'Liberal Peace." International Peacekeeping 11, no. 1 (Spring): 59-81.

Chesterman, Simon. 2011. "Leading from Behind': The Responsibility to Protect, the Obama Doctrine, and Humanitarian Intervention After Libya.". New York University Public Law and Legal Theory Working Papers. Paper 282.

CIA. 2013. "The World Factbook." Accessed December 30, 2013. https://www.cia.gov/library/publications/the-worldfactbook/geos/sy.html.

Coady, C. A. J.. 2008. Morality and political violence. Cambridge: Cambridge 
University Press.

Contarino, Michael and Selena Lucent. 2010. "Stopping the Killing: The International Criminal Court and Juridical Determination of the Responsibility to Protect" in The Responsibility to Protect and International Law, eds. Alex J. Bellamy, Sara E. Davies and Luke Glanville (Leiden, The Netherlands: Martinus Nijhoff Publishers).

De Waal, Alex. 2007. "Darfur And The Failure Of The Responsibility To Protect." International Affairs 83, no. 6: 1039-1054.

Deller, Nicole. 2011. "Challenges and Controversies," in The Responsibility to Protect: The Promise of Stopping Mass Atrocities in Our Time, eds. Jared Genser and Irwin Cotler (Oxford University Press).

Eckert, Amy. 2012. "The Responsibility to Protect in the Anarchical Society: Power, Interest, and the Protection of Civilians in Libya and Syria." Denver Journal of International Law and Policy 41, no. 1: 87-99.

Evans, Gareth and Mohamed Sahnoun. 2002. "The Responsibility to Protect.” Foreign Affairs 81, no. 6: 99-110.

Falk, Richard A.. 1999. "Kosovo, World Order, and the Future of International Law." The American Journal of International Law 93, no. 4: 847-857.

Farer, T. J., Daniele Archibugi, Chris Brown, Neta C. Crawford, Thomas Weiss, and Nicholas Wheeler. 2005. "Roundtable: Humanitarian Intervention After 9/11." International Relations 19, no. 2: 211-250. 
Fassbender, Bardo. 2003. “All Illusions Shattered? Looking Back on a Decade of Failed Attempts to Reform the UN Security Council." Max Planck Yearbook of United Nations Law vol. 7: 183-218.

Ferris, Elizabeth G.. 2011. The politics of protection the limits of humanitarian action. Washington, D.C.: Brookings Institution Press.

Finnemore, Martha. 2003. The purpose of intervention: changing beliefs about the use of force. Ithaca: Cornell University Press.

Fisher, Eloy. 2008. “United Nations Security Council (UNSC) reform and international political decision making: A theoretical approximation." REVISTA PANAMEÑA DE POLÍTICA 6, July - December: 73-87.

Glanville, Luke. 2013. “Intervention in Libya: From Sovereign Consent to Regional Consent." International Studies Perspectives 14: 325-342.

Groves, Steven. 2008. “The U.S. Should Reject the U.N. 'Responsibility to Protect' Doctrine." Backgrounder, Published by the Heritage Foundation 2130: 1-12.

Groves, Steven. 2011. “Obama Wrongly Adopts U.N. 'Responsibility to Protect' to Justify Libya Intervention." Web Memo Published by the Heritage Foundation. Accessed October 5, 2013. http://report.heritage.org/wm3210.

Henkin, Louis. 1999. “Kosovo and the Law of 'Humanitarian Intervention.'” The American Journal of International Law 93, no. 4: 824-828.

Hoffman, Walter and Ayca Ariyoruk. 2005. “Security Council Reform Models” Special Paper No. 4. Center for UN Education. 
Hurd, Ian. 2007. After Anarchy: Legitimacy and Power in the United Nations Security Council. Princeton, NJ: Princeton University Press.

International Commission on Intervention and State Sovereignty. 2001. The

Responsibility to Protect: Report of the International Commission on Intervention and State Sovereignty. Ottawa, ON, Canada: International Development Research Centre.

International Commission on Intervention and State Sovereignty. 2001a. The Responsibility to Protect: Supplementary Volume to the Report of the International Commission on Intervention and State Sovereignty. Ottawa, ON, Canada: International Development Research Centre.

International Independent Commission on Kosovo. 2000. The Kosovo Report: Conflict, International Response, Lessons Learned. New York, N.Y.: Oxford University Press.

Kant, Immanuel. 2002. Groundwork for the Metaphysics of Morals. Translated by Allen W. Wood. Binghamton, NY: Vail-Ballou Press.

Kohen, M. G., and Katherine Del Mar. 2011. “The Kosovo Advisory Opinion and UNSCR 1244 (1999): A Declaration of 'Independence from International Law'?" Leiden Journal of International Law 24, no. 1: 109-126.

Krasner, Stephen D.. 1999. Sovereignty: organized hypocrisy. Princeton, N.J.: Princeton University Press. 
Lambourne, Wendy and Annie Herro. 2008. "Peacebuilding theory and the United Nations Peacebuilding Commission: implications for non-UN interventions." Global Change, Peace \& Security 20, no. 4: 275-289.

Legal Information Institute. 2014. “Opinio Juris (International Law)." Accessed January 23, 2014. http://www.law.cornell.edu/wex/opinio_juris_international_law.

Luck, Edward. 2010. "Sovereignty, Choice, and the Responsibility to Protect," in The Responsibility to Protect and International Law, eds. Alex J. Bellamy, Sara E. Davies and Luke Glanville (Leiden, The Netherlands: Martinus Nijhoff Publishers).

Luck, Edward. 2011. "The Responsibility to Protect: The First Decade." Global Responsibility to Protect 3: 1-13.

Martini, Elisabetta. 2009. "UN Security Council Reform: Current Developments." Instituto Affari Internazionali. Accessed January 23, 2013. http://www.iai.it/pdf/DocIAI/iai0926.pdf.

Morris, Justin. 2013. "Libya and Syria: R2P and the spectre of the swinging pendulum." International Affairs 89, no. 5: 1265-1283.

Nahory, Celine. 2004. "The Hidden Veto." Global Policy Forum. Accessed December 2, 2012. http://www.globalpolicy.org/component/content/ article/185/42656.html.

Nuruzzaman, Mohammed. 2013. “The 'Responsibility to Protect Doctrine: Revived in Libya, Buried in Syria." Insight Turkey 15, no. 2: 57-66. 
Obama, Barack. 2011. "Remarks by the President in Address to the Nation on Libya." Speech, Washington, D.C., March 28, 2011. http://www.whitehouse.gov/thepress-office/2011/03/28/remarks-president-address-nation-libya.

Rawls, John. 1971. A theory of justice. Cambridge, MA: Belknap Press of Harvard University Press.

Rosenberg, Sheri P.. 2010. "Responsibility to Protect: A Framework for Prevention," in The Responsibility to Protect and International Law, eds. Alex J. Bellamy, Sara E. Davies and Luke Glanville (Leiden, The Netherlands: Martinus Nijhoff Publishers).

Security Council Report. 2013. "The Security Council and the UN Peacebuilding Commission." Special Research Report April 2013, no. 1.

Stahn, Carsten. 2007. "Responsibility to Protect: Political Rhetoric or Emerging Legal Norm?" The American Journal of International Law 101, no. 99: 99-120.

Strauss, E.. 2010. "A Bird in the Hand is Worth Two in the Bush - On the Assumed Legal Nature of the Responsibility to Protect," in The Responsibility to Protect and International Law, eds. Alex J. Bellamy, Sara E. Davies and Luke Glanville (Leiden, The Netherlands: Martinus Nijhoff Publishers).

Thakur, Ramesh. 2009. "Humanitarian Intervention," in The Oxford Handbook on the United Nations, eds. Sam Daws and Thomas Weiss (Oxford University Press), accessed April 17, 2013, http://www.oxfordhandbooks.com/view/10.1093/oxfordhb/97801995601 03.001.0001/oxfordhb-9780199560103-e-022. 
Vranes, E.. 2006. "The Definition Of 'Norm Conflict' In International Law And Legal Theory." European Journal of International Law 17, no. 2: 395-418.

Walzer, Michael. 1994. Thick and thin: moral argument at home and abroad. Notre Dame: University of Notre Dame Press.

Weiss, Thomas G.. 2003. "The Illusion of UN Security Council Reform." Washington Quarterly 26, no. 4: 147-161.

Weiss, Thomas G.. 2004. "The Sunset Of Humanitarian Intervention? The Responsibility To Protect In A Unipolar Era." Security Dialogue 35, no. 2: 135153.

Weiss, Thomas G. and Young, Karen. 2005. "Compromise and Credibility: Security Council Reform?" Security Dialogue 36, no. 2: 131-154.

Weiss, Thomas, Ramesh Thakur, Mary Ellen O'Connell, Aidan Hehir, Alex J. Bellamy, David Chandler, Rodger Shanahan, Rachel Gerber, Abiodun Williams, and Gareth Evans. 2011. "The Responsibility to Protect: challenges and opportunities in light of the Libyan intervention." e-International Relations. Accessed January 23, 2014. http://www.e-ir.info/wpcontent/uploads/R2P.pdf.

Welsh, Jennifer M. and Maria Banda. 2010. "International Law and the Responsibility to Protect: Clarifying or Expanding States' Responsibilities?" in The Responsibility to Protect and International Law, eds. Alex J. Bellamy, Sara E. Davies and Luke Glanville (Leiden, The Netherlands: Martinus Nijhoff Publishers). 
United Nations. 1945. Charter of the United Nations.

UN News Centre. 2012. "UN-backed Action Group agrees on measures for peaceful transition in Syria." Accessed January 23, 2014. http://www.un.org/apps/news/story.asp/www.iaea.org/html/www.fao.org /story.asp?NewsID=42367\&Cr=Syria\&Cr1=\#.UuGcfPTTmIV.

U. N. General Assembly, Hundred and seventy-ninth plenary meeting. 1948.

"Prevention and punishment of the crime of genocide." 9 December 1948.

U. N. General Assembly, Fifty-ninth session. 2004. "A more secure world: our shared responsibility" (A/59/565). 2 December 2004.

U. N. General Assembly, Sixtieth session. 2005. "2005 World Summit Outcome" (A/60/L.1). 15 September 2005.

U. N. General Assembly, Fifty-ninth session. 2005a. "In larger freedom: towards development, security and human rights for all" (A/59/2005). 21 March 2005.

U. N. General Assembly, Sixty-seventh session. 2013. "Scale of assessments for the apportionment of the expenses of the United Nations" (A/RES/67/238). 11 February 2013.

U. N. Security Council, 3868th Meeting. 1998. "Resolution 1160" (S/RES/1160). 31 March 1998.

U. N. Security Council, 3930th Meeting. 1998. "Resolution 1199” (S/RES/1199). 23 
September 1998.

U. N. Security Council, 4011th Meeting. 1999. "Resolution 1244" (S/RES/1244). 10 June 1999.

U.N. Security Council, 5335th Meeting. 2005. "Resolution 1645" (S/RES/1645). 20 December 2005.

U. N. Security Council, 5430th Meeting. 2006. "Resolution 1674" (S/RES/1674). 28 April 2006.

U. N. Security Council, 6491st Meeting. 2011. "Resolution 1970” (S/RES/1970). 26 February 2011.

U. N. Security Council, 6498th Meeting. 2011a. "Resolution 1973" (S/RES/1973). 17 March 2011.

U.N. Security Council, 7038th Meeting. 2013. "Resolution 2118" (S/RES/2118). 27 September 2013. 